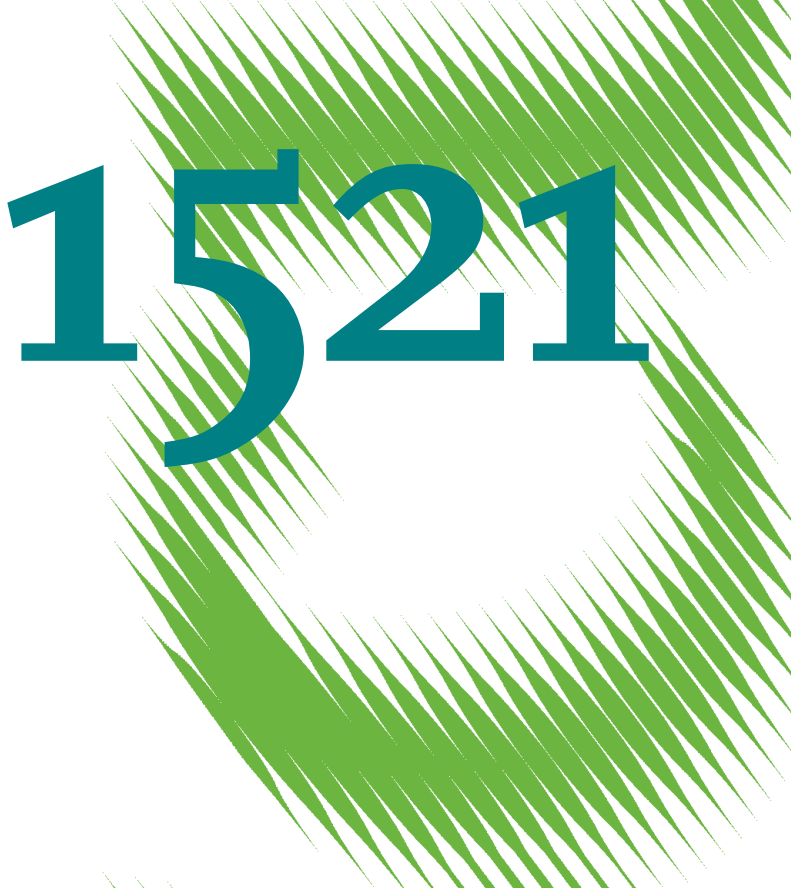

The Impact of Policy Measures on Future Power Generation Portfolio and Infrastructure A Combined Electricity and CCTS Investment and Dispatch Model (ELCO) 
Opinions expressed in this paper are those of the author(s) and do not necessarily reflect views of the institute.

IMPRESSUM

(C) DIW Berlin, 2015

DIW Berlin

German Institute for Economic Research

Mohrenstr. 58

10117 Berlin

Tel. +49 (30) $89789-0$

Fax +49 (30) $89789-200$

http://www.diw.de

ISSN electronic edition 1619-4535

Papers can be downloaded free of charge from the DIW Berlin website:

http://www.diw.de/discussionpapers

Discussion Papers of DIW Berlin are indexed in RePEc and SSRN:

http://ideas.repec.org/s/diw/diwwpp.html

http://www.ssrn.com/link/DIW-Berlin-German-Inst-Econ-Res.html 


\title{
The Impact of Policy Measures on Future Power Generation Portfolio and Infrastructure - A Combined Electricity and CCTS Investment and Dispatch Model (ELCO)
}

\author{
Roman Mendelevitch ${ }^{1}$, Pao-Yu Oei ${ }^{2}$
}

\begin{abstract}
:
This paper presents a general electricity- $\mathrm{CO}_{2}$ (ELCO) modeling framework that is able to simulate interactions of the energy-only market with different forms for national policy measures. We set up a two sector model where players can invest into various types of generation technologies including renewables, nuclear and Carbon Capture, Transport, and Storage (CCTS). For a detailed representation of CCTS we also include industry players (iron and steel as well as cement), and $\mathrm{CO}_{2}$ transport and $\mathrm{CO}_{2}$ storage including the option for $\mathrm{CO}_{2}$ enhanced oil recovery $\left(\mathrm{CO}_{2}\right.$-EOR). The players maximize their expected profits based on variable, fixed and investment costs as well as the price of electricity, $\mathrm{CO}_{2}$ abatement cost and other incentives, subject to technical and environmental constraints. Demand is inelastic and represented via a selection of type hours. The model framework allows for regional disaggregation and features simplified electricity and $\mathrm{CO}_{2}$ pipeline networks. The model is balanced via a market clearing for the electricity as well as $\mathrm{CO}_{2}$ market. The equilibrium solution is subject to constraints on $\mathrm{CO}_{2}$ emissions and renewable generation share. We apply the model to a case study of the UK Electricity Market Reform to illustrate the mechanisms and potential results attained from the model.
\end{abstract}

Keywords: Energy policy, electricity, $\mathrm{CO}_{2}, \mathrm{CCS}$, UK, EOR, modeling

JEL: C61, L94, O33, Q42

\footnotetext{
${ }^{1}$ Corresponding author: DIW Berlin, Mohrenstrasse 58, 10117 Berlin, +49 3089789-206; rmendelevitch@diw.de and TU Berlin, Strasse des 17. Juni 135, 10623 Berlin; Roman.Mendelevitch@tu-berlin.de.

2 TU Berlin, Strasse des 17. Juni 135, 10623 Berlin; pyo@wip.tu-berlin.de and DIW Berlin, Mohrenstrasse 58, 10117 Berlin, poei@diw.de.
} 



\section{Introduction}

The need for combating climate change is internationally widely accepted (World Summit of the Regions 2014) and the role of the electricity sector as a major contributor to global GHG emission reductions is undisputed (Leader of the G7 2015). However, there exists an international dissent on how to achieve a decarbonization of the sector. Even in the EU, a multitude of approaches exist: Germany has departed on its "Energiewende" path towards a renewable energy based system, with renewable energy sources (RES) already contributing to $30 \%$ of electricity production in 2015 . At the same time, France still relies on large nuclear capacities; while the United Kingdom (UK) promotes a mixed strategy of renewables, nuclear and carbon capture, transport, and storage (CCTS). The low certificate prices in the European Emissions Trading System (EU-ETS), at levels below $10 € / \mathrm{tCO}_{2}$ in 2015 - with little hope for a significant rise in the upcoming years ( $\mathrm{Hu}$ et al. 2015) - however gives insufficient incentives for most of these low-carbon investments. This endangers achieving the EU climate policy targets for 2030 (EC 2014) and puts the global $2^{\circ} \mathrm{C}$ target at risk. Therefore, several countries have started or are about to start backing the EU-ETS with additional national measures. These include different types of feed-in tariffs and market premia, capacity markets, a minimum $\mathrm{CO}_{2}$ price and emissions performance standards (EPS). Models assessing the future development of a decarbonized electricity market need to adequately incorporate such additional policy measures. In addition, interdependencies between the measures as well as feedbacks with other sectors need to be taken into account.

Different kinds of models are used to assess the impact of policy instruments and their ability to achieve climate change policy objectives. Pfenninger et al. (2014) classify models according to the different challenges they address. They differentiate between energy system models for normative scenarios, energy system simulation models for forecasts, power systems and electricity market models for analyzing operational decisions and qualitative and mixed-methods for narrative scenarios. Energy system models such as PRIMES (Capros et al. 1998), MARKAL (Fishbone and Abilock 1981), EFOM (Finon 1979) or POLES (Criqui 1996) are able to convey the "big picture" of what is happening in different linked sectors of an energy system. These technology-oriented models focus on the energy conversion system, on the demand-side (e.g. efficiency measures) as well as supply side (e.g. wide range of generation technologies). The advantages of these models are that they cover several sectors, linking them through endogenous fuel substitution. They are mostly solved by optimization or simulation techniques when minimizing system costs or maximizing the overall welfare. Fais et al. (2014) integrate different types of RES support schemes such as feed-in tariffs as well as quantity based instruments such as certificate systems in their energy system model Times-D. Their approach can be used to analyze exogenous support scheme but does not establish a link between attaining a specific $\mathrm{CO}_{2}$ target and the level of required RES support, and does not allow analysis of long-term development. Moreover, RES generation is limited exogenously via upper bounds on annual maximum expansion. They assume perfect competition and have limited possibilities to incorporate market power.

Apart from energy system models, there is a large strand of literature that employs a partial equilibrium setting to assess one particular market, e.g. the electricity market. This allows for analyzing non-cooperative firm behavior in more detail (e.g. à la Cournot) by allowing the 
firms to strategically exploit their influence on the market price with their output decision. Moreover, different risk attitudes and explicit shadow prices can be easily incorporated in these settings. The models have been focusing on considerations of resource adequacy (Ehrenmann and Smeers 2011), assessing the impact of environmental regulation (Allevi, Bonenti, and Oggioni 2013), renewables obligations and portfolio standards (see e.g. Gürkan and Langestraat 2014; Chen and Wang 2013), or congestion management of the transmission network (Kunz and Zerrahn 2015).

One technology that is of particular interest for a future decarbonization of the electricity sector is CCTS. The technology comes with a dichotomy: On the one hand, it plays an important role in many of the possible energy system scenarios that are consistent with the EU Energy Roadmap (EC 2013). Accordingly, the scenarios for the newest report from the IPCC (2014) estimate a cost increase of $29-297 \%$ for reaching the $2^{\circ} \mathrm{C}$ target without the CCTS technology. ${ }^{3}$ On the other hand, despite available financial schemes and technology, CCTS has not been implemented on a large scale anywhere in the world. Various authors have addressed this discrepancy with different regional focuses (Groenenberg and de Coninck 2008; Hirschhausen, Herold, and Oei 2012; Milligan 2014; Stechow, Watson, and Praetorius 2011). Gale et al. (2015) in addition address this topic in a special issue commemorating the $10^{\text {th }}$ anniversary of the first IPCC (2005) special report on CCTS.

Most electricity market models do not put any emphasis on CCTS, and handle the technology like any other conventional generation technology by specifying investment and variable costs and fuel efficiency. For example, Eide et al. (2014) apply a stochastic generation expansion model to determine the impact of $\mathrm{CO}_{2}$ EPS on electricity generation investment decisions in the U.S. Their findings show a shift from fossil fuel generation from coal to natural gas rather than incentivizing investment in CCTS. Zhai and Rubin (2013) explored the "tipping point" in natural gas prices for which a coal plant with CCTS becomes economically competitive, as a function of an EPS. Middleton and Eccles (2013) calculate the price for $\mathrm{CO}_{2}$ to be in the range of $85-135 \cup S \$ / \mathrm{tCO}_{2}\left(65-105 € / \mathrm{tCO} \mathrm{CO}_{2}\right)$ to incentivize a gas power plant to use CCTS in the USA. This simplified representation of the CCTS technology in these models, however, neglects transportation and storage aspects as well as the possibility of industrial usage of CCTS.

By contrast, if models focus on CCTS infrastructure development, they often neglect how the technology is driven by decisions in the electricity market. A series of studies analyzed the technical potential of CCTS deployment, including possible $\mathrm{CO}_{2}$ pipeline routing (Oei, Herold, and Mendelevitch 2014; Morbee, Serpa, and Tzimas 2012; Middleton and Bielicki 2009; Kazmierczak et al. 2008; Kobos et al. 2007). The construction of such large-scale new infrastructure networks is highly influenced by public acceptance, especially in densely populated regions such as the European Union (Gough, O'Keefe, and Mander 2014). Acceptance issues as well as other technical uncertainties can lead to high cost increases of a CCTS deployment (Knoope, Ramírez, and Faaij 2015). In the absence of expected

\footnotetext{
${ }^{3}$ RES and nuclear provide decarbonization alternatives for the electricity sector. The high cost increase, however, is caused by only limited alternative decarbonization technologies in the industry sector. Negative emissions of large-scale utilization of CCTS with biomass, in addition, compensate for unabatable emissions in other sectors (Kemper 2015).
} 
technological learning and with persistently low $\mathrm{CO}_{2}$ certificate prices CCTS projects aim at additional income through $\mathrm{CO}_{2}$-Enhanced Oil Recovery $\left(\mathrm{CO}_{2}\right.$-EOR) (Mendelevitch 2014; Kemp and Kasim 2013).

Kjärstad et al. (2013) have started to close this gap by combining the techno-economic Chalmers Electricity Investment Model with InfraCCS, a cost optimization tool for bulk $\mathrm{CO}_{2}$ pipelines along with Chalmers databases on power plants and $\mathrm{CO}_{2}$ storage sites. Their approach, however, relies on sequentially solving both sectors independent from one another. They in addition do not include $\mathrm{CO}_{2}$ capture from industrial sources which leads to economies of scale especially with respect to transporting $\mathrm{CO}_{2}$ but also goes along with scarcity effects with respect to $\mathrm{CO}_{2}$ storage. Additional research is needed to include different policy instruments into the modeling frameworks to evaluate the effect of various measures.

This paper presents a general electricity- $\mathrm{CO}_{2}$ (ELCO) modeling framework that is able to simulate interactions of the energy-only market with different forms for national policy measures as well as a full representation of the carbon capture, transport, and storage (CCTS) chain. Different measures included in the model are feed-in tariffs, a minimum $\mathrm{CO}_{2}$ price and a $\mathrm{CO}_{2}$ emissions performance standard (EPS). Additionally, the model includes large industrial emitters from the iron/steel and cement sector that might also invest in carbon captures facilities, increasing scarcity effects for $\mathrm{CO}_{2}$ storage. The set-up also takes into account demand variation by type hours, the availability of more and less favorable locations for RES and endogenously accounts for limits to annual diffusion of new technologies. The model is driven by a $\mathrm{CO}_{2}$ target and an optional RES target. This paper is used to describe the different features and potentials of the ELCO model. We apply the model to a stylized case study of the UK Electricity Market Reform (EMR) to present a show case of our model framework.

The remaining paper is structured as follows: The introduction is followed by a detailed description of the ELCO model in section 2. A case study in section 3 applies the ELCO model to the UK electricity market. The main policy measures are adjusted in the model to mimic the UK EMR and its long-term effects. Section 4 concludes with an outlook of future applications of the ELCO model.

\section{Mathematical representation of the ELCO model}

The ELCO model mimics the competition of different conventional electricity generation technologies on the electricity market and their interaction with new technologies that are financed via fixed tariffs. Each technology is represented via a stylized player that competes with one another. For a better representation of scarce $\mathrm{CO}_{2}$ storage resources we also include a detailed representation of the complete CCTS value chain. This also includes potential $\mathrm{CO}_{2}$ capture from the steel and cement industry. The different $\mathrm{CO}_{2}$ storage options such as $\mathrm{CO}_{2}$-EOR, saline aquifers and depleted oil and gas reservoirs compete against one another in the last stage of the CCTS value chain. All players maximize their respective profits subject to their own as well as joint technical and environmental constraints. Other (external) costs as well as further welfare components are not being analyzed. Regional disaggregation takes into account geographical characteristics like availability (especially 
with respect to maximum potential and conditions for renewables as well as $\mathrm{CO}_{2}$ storage) and specific electricity demand.

Different policy measures such as a Carbon Price Floor (CPF), an Emissions Performance Standard (EPS) or feed-in tariffs in form of Contracts for Differences (CfD) are included in the modeling framework. The ELCO model analyzes how these policy instruments will influence the construction of new generation capacities. CfD for newly constructed low-carbon technologies can be derived endogenously using shadow variables of constraints. Assuming perfect competition between the different players, equilibrium is reached when overall system costs are being minimized subject to all constraints.

The developed model is able to assess regionally disaggregated investment in electricity generation, generation dispatch and simplified flows as well as $\mathrm{CO}_{2}$ transport, storage, and usage for $\mathrm{CO}_{2}$-EOR. Incorporating $\mathrm{CO}_{2}$ capture by industrial facilities from the steel, and cement sector enables, on the one hand, the representation of economies of scale along the transport routes while, on the other hand, leading to higher scarcity effects with respect to $\mathrm{CO}_{2}$ storage options.

\subsection{Notations of the model}

The following tables list the used sets, variables and parameters of the ELCO Model. Parameters are indicated by capital letters, variables by small sized letters and sets are resembled in subscripts. The detailed Karush-Kuhn-Tucker (KKT) conditions of the ELCO model are depicted in the Appendix 7.

\begin{tabular}{l|l}
\hline Name & Description \\
\hline a, aa, aaa & 5 year period \\
h, hh & Time interval \\
$\mathrm{i}, \mathrm{ii}$ & $\mathrm{CO}_{2}$ sources from industry $\{$ Steel: IND_ST, Cement: IND_CE\} \\
$\mathrm{n}, \mathrm{nn}$ & Node \\
new(t) & Flag if a technology is newly built $\{0,1\}$ \\
$\mathrm{s}, \mathrm{ss}$ & $\mathrm{CO}_{2}$ sinks $\{$ Saline: STO_SA, DOGF: STO_DA, EOR: STO_SA\} \\
$\mathrm{t}, \mathrm{tt}$ & Generation technologies: \{ \\
& - g-type existing capacities: Nuc, Coal, Gas_GT: CCGT, Gas_CC: \\
& OCGT; \\
& - g-type new capacities: COAL_NEW, CCGT_NEW, OCGT_NEW; \\
& - g_cfd-type new capacities: PV: RES_PV, Wind_on: RES_WI_ON, \\
& Wind_off: RES_WI_OF, Hydro: RES_HY, Biomass: RES_BI, \\
& Coal_CCTS, CCGT_CCTS $\}$ \\
\hline
\end{tabular}

Table 1: List of sets of the ELCO Model

\begin{tabular}{|c|c|c|}
\hline Name & Description & Unit \\
\hline co2_c(h,n,i,a) & Emissions captured from industry & {$\left[\mathrm{ktCO}_{2} / \mathrm{h}\right]$} \\
\hline co2_s(h,n,s,a) & Storaged emissions & {$\left[\mathrm{ktCO}_{2} / \mathrm{h}\right]$} \\
\hline co2_t $t(h, n, n n, a)$ & Flow of $\mathrm{CO}_{2}$ & {$\left[\mathrm{ktCO}_{2}\right]$} \\
\hline el_t(h,n,nn,a) & Flow of electricity & {$[\mathrm{GW}]$} \\
\hline emps(a) & Emissions Performance Standard & {$\left[\mathrm{ktCO}_{2} / \mathrm{GWh}\right]$} \\
\hline$g(h, n, t, a)$ & Generation of electricity & [GW] \\
\hline g_cfd(h,n,t,aa,a) & Generation electricity from CfD sources & [GW] \\
\hline inv_co2_c(n,i,a) & Investment in capture technology & {$\left[\mathrm{k} € / \mathrm{ktCO}_{2} / \mathrm{h}\right]$} \\
\hline inv_co2_s(n,s,a) & Investment in storage technology & {$\left[\mathrm{k} \in / \mathrm{ktCO}_{2} / \mathrm{h}\right]$} \\
\hline inv_co2_t $(n, n n, a)$ & Investment in $\mathrm{CO}_{2}$ transport capacity & {$\left[\mathrm{k} € / \mathrm{ktCO}_{2} / \mathrm{h}\right]$} \\
\hline inv_el_t $(\mathrm{n}, \mathrm{nn}, \mathrm{a})$ & Investment in electricity transport capacity & {$[\mathrm{k} € / G W]$} \\
\hline inv_g(n,t,a) & Investment in generation capacity & {$[k \in / G W]$} \\
\hline
\end{tabular}

Table 2: List of variables of the ELCO Model 


\begin{tabular}{|c|c|c|}
\hline Name & Description & Unit \\
\hline lambda cap co2 c(h,n,i,a) & Dual of $\mathrm{CO}_{2}$ capture cap. & {$\left[\mathrm{k} \in / \mathrm{ktCO}_{2} / \mathrm{h}\right]$} \\
\hline lambda_cap_co2_s(h,n,s,a) & Dual of $\mathrm{CO}_{2}$ annual storage cap. & {$[\mathrm{k} \in / \mathrm{ktCO} / \mathrm{h}]$} \\
\hline lambda_cap_co2_t $(\mathrm{h}, \mathrm{n}, \mathrm{nn}, \mathrm{a})$ & Dual of $\mathrm{CO}_{2}$ transport cap. & {$[\mathrm{k} \in / \mathrm{ktCO} / \mathrm{h}]$} \\
\hline lambda_cap_el_t(h,n,nn,a) & Dual of transmission cap. & {$[k \in / G W]$} \\
\hline lambda_cap_g( $\bar{h}, \mathrm{n}, \mathrm{t}, \mathrm{a})$ & Dual of elec. generation cap. & {$[k \in / G W]$} \\
\hline lambda_cap_g_cfd(h,n,t,aa,a) & Dual of elec. must run condition for RES & {$[k \in / G W]$} \\
\hline lambda_curt_el(h,a) & Dual of electricity curtailment & {$[\mathrm{k} \in / \mathrm{GWh}]$} \\
\hline lambda_diff_co2_c(i,a) & Dual of diffusion for $\mathrm{CO}_{2}$ capture in industry & {$\left[\mathrm{k} \in / \mathrm{ktCO}_{2} / \mathrm{h}\right]$} \\
\hline lambda_diff_co2_s(s,a) & Dual of diffusion for $\mathrm{CO}_{2}$ storage & {$[\mathrm{k} \in / \mathrm{ktCO} / \mathrm{h}]$} \\
\hline lambda_diff_g(t,a) & Dual of diffusion for renewables & {$[\mathrm{k} \in / \mathrm{GWh}]$} \\
\hline lambda_emps(n,t,a) & Dual of emps constraint & {$\left[\mathrm{k} \in / \mathrm{ktCO}_{2}\right]$} \\
\hline lambda_max_ind(h,n,i,a) & Dual of maximum industry emissions & {$\left[\mathrm{k} \in / \mathrm{ktCO}_{2} / \mathrm{h}\right]$} \\
\hline lambda_max_stor(n,s,a) & Dual of max. $\mathrm{CO}_{2}$ storage cap. & {$[\mathrm{k} \in / \mathrm{ktCO} / \mathrm{h}]$} \\
\hline lambda_pot_g(n,t,a) & Dual of potential for renewables & {$[\mathrm{k} \in / \mathrm{GW}]$} \\
\hline lambda_target_co2(a) & Dual of $\mathrm{CO}_{2}$ emissions constraint & {$\left[\mathrm{k} \in / \mathrm{ktCO}_{2}\right]$} \\
\hline lambda_target_RE(a) & Dual of renewables target constraint & {$[k \in / G W h]$} \\
\hline mu_co2(h,n,a) & Dual of $\mathrm{CO}_{2}$ market clearing & {$[\mathrm{k} \in / \mathrm{ktCO} / \mathrm{h}]$} \\
\hline mu_el(h,n,a) & Dual of electricity market clearing & {$[\mathrm{k} \in / \mathrm{GWh}]$} \\
\hline
\end{tabular}

Table 3: List of dual variables of the ELCO Model

\begin{tabular}{|c|c|c|}
\hline Name & Description & \\
\hline ADJ CO2(n,nn) & Flag if two $\mathrm{CO}_{2}$-nodes are adjacent & $\{0,1\}$ \\
\hline ADJ_EL(n,nn) & Flag if two Elec-nodes are adjacent & $\{0,1\}$ \\
\hline $\mathrm{ALP} \overline{\mathrm{H}} \mathrm{A}(\mathrm{t}, \mathrm{a})$ & Maximal marginal $\mathrm{CO}_{2}$-abatement & {$\left[\mathrm{ktCO}_{2} / \mathrm{GWh}\right]$} \\
\hline $\operatorname{AVAIL}(\mathrm{h}, \mathrm{n}, \mathrm{t})$ & Availability of power plant & [\%] \\
\hline CO2_IND $(h, n, i, a)$ & $\mathrm{CO}_{2}$ emission by industry & {$\left[\mathrm{ktCO}_{2}\right]$} \\
\hline CO2_TARGET(a) & $\mathrm{CO}_{2}$ target reduction for electricity sources & [\%] \\
\hline $\mathrm{CP}$ & Planning and construction period & [years] \\
\hline $\mathrm{CP}^{-} \mathrm{G}(\mathrm{t})$ & Planning and construction period & [years] \\
\hline CPS̄ $(a)$ & Carbon price support & {$\left[\mathrm{k} \in / \mathrm{ktCO}_{2}\right]$} \\
\hline CR_G(t) & Capture rate for generation & $90 \%$ or $0 \%$ \\
\hline CR_IND(i) & Capture rate for industries & $90 \%$ \\
\hline$D(h, n, a)$ & Electricity demand & [GW] \\
\hline $\mathrm{DF}(\mathrm{a})$ & Discount factor & [\%] \\
\hline DIFF_CO2(s/i) & $\begin{array}{l}\text { Technology diffusion factor storage / industry } \\
\text { capture }\end{array}$ & [\%] \\
\hline DIFF_G(t) & $\begin{array}{l}\text { Technology diffusion factor by generation } \\
\text { technology }\end{array}$ & [\%] \\
\hline$E F E L(t)$ & Emissions factor & {$[\mathrm{ktCO} / \mathrm{GWh}]$} \\
\hline EFF_COO2 & $\mathrm{CO}_{2}$-EOR efficiency & {$\left[\mathrm{kbbl} / \mathrm{ktCO}{ }_{2}\right]$} \\
\hline EUA(a) & EU-ETS allowances & {$\left[\mathrm{k} \in / \mathrm{ktCO}{ }_{2}\right]$} \\
\hline FC_CO2(n,s/i,a) & Fix costs for $\mathrm{CO}_{2}$ capture, and storage & {$\left[\mathrm{k} \in / \mathrm{ktCO}_{2}\right]$} \\
\hline $\mathrm{FC}_{-} \mathrm{CO} 2 \_\mathrm{T}(\mathrm{n}, \mathrm{nn})$ & Fix costs for $\mathrm{CO}_{2}$ transport & {$\left[\mathrm{k} \in / \mathrm{ktCO}_{2}\right]$} \\
\hline FC_F_E(n, nn) & Fix costs for electricity transport & {$[\mathrm{k} \in / \mathrm{GW}]$} \\
\hline$F C_{-} G(n, t, a)$ & Fix costs for generation w/o. or w/ capture & {$[k \in / G W]$} \\
\hline I_USE_CO2(s/i,a,aa) & $\begin{array}{l}\text { Flag if capacity investment from year a can be } \\
\text { used for generation in year aa in the } \mathrm{CO}_{2} \\
\text { sector }\end{array}$ & $\{0,1\}$ \\
\hline I_USE_EL(t,a,aa) & $\begin{array}{l}\text { Flag if capacity investment from year a can be } \\
\text { used for generation in year aa in the electricity } \\
\text { sector }\end{array}$ & $\{0,1\}$ \\
\hline INICAP_EL_T(n,nn) & Initial capacity for electricity transport & [GW] \\
\hline INICAP_G(- & Initial capacity incl. retirement & [GW] \\
\hline INTC $\overline{\mathrm{CO} 2}(\mathrm{t})$ & Quadratic cost term for $\mathrm{CO}_{2}$ operation & {$\left[\mathrm{k} \in / G W h^{2}\right]$} \\
\hline INTC_G(t) & $\begin{array}{l}\text { Quadratic integration costs for generation } \\
\text { technologies }\end{array}$ & {$\left[k \in / G W h^{2}\right]$} \\
\hline
\end{tabular}




\begin{tabular}{|c|c|c|}
\hline Name & Description & \\
\hline INVC_CO2(n,s/i,a) & $\begin{array}{l}\text { Investment cost for industrial } \mathrm{CO}_{2} \text { capture } \\
\text { capacity or storage per hour }\end{array}$ & {$\left[\mathrm{k} \in / \mathrm{ktCO}_{2} / \mathrm{h}\right]$} \\
\hline INVC CO2 T(n,nn) & Investment cost for $\mathrm{CO}_{2}$ transport & {$\left[\mathrm{k} \in / \mathrm{ktCO}_{2} / \mathrm{h}\right]$} \\
\hline INVC_EL_T(n,nn) & Investment cost for electricity transport & {$[k \in / G W]$} \\
\hline INVC_G(n,t,a) & $\begin{array}{l}\text { Investment cost for generation capacity w/o or } \\
\text { w/ capture }\end{array}$ & {$[\mathrm{k} \in / G W]$} \\
\hline LT_CO2(s/i) & $\begin{array}{l}\text { Life time of industry } \mathrm{CO}_{2} \text { capture \& storage } \\
\text { technology }\end{array}$ & [years] \\
\hline LT_G(t) & Life time of generation technology & [years] \\
\hline$M \overline{A X} I N V(n, t)$ & Maximal potential of generation technology & [GW] \\
\hline MAX_STOR(n,s) & Maximal $\mathrm{CO}_{2}$ storage capacity & {$\left[\mathrm{ktCO}{ }_{2}\right]$} \\
\hline OILPRICE(a) & Price of additional oil from $\mathrm{CO}_{2}$-EOR & {$[\mathrm{k} \in / \mathrm{kbbl}]$} \\
\hline ONE_FUEL(t,tt) & Flag for identical fuel & $\{0,1\}$ \\
\hline $\mathrm{PD}(\mathrm{a})$ & Period duration (5 years) & [years] \\
\hline RE TARGET(a) & Renewables target & [\%] \\
\hline REF__CO2 & $\begin{array}{l}\mathrm{CO}_{2} \text { emissions from electricity generation in } \\
1990\end{array}$ & {$\left[\mathrm{ktCO}_{2}\right]$} \\
\hline RES_OLD(h,n,a) & Generation of already existing RE & [GW] \\
\hline $\mathrm{SP}(\mathrm{t}, \bar{a})$ & Strike price for CfD-technologies in first years & {$[k \in / G W h]$} \\
\hline START_CO2(s/i) & $\begin{array}{l}\text { Starting capacity industry capture \& storage } \\
\text { technology }\end{array}$ & {$\left[\mathrm{ktCO}_{2} / \mathrm{h}\right]$} \\
\hline START_G(t) & Starting capacity for generation technology & [GW] \\
\hline $\mathrm{TD}(\mathrm{h})$ & Time duration of each hourly segment & [hours] \\
\hline USE_CO2(s/i,a,aa) & $\begin{array}{l}\text { Flag if capacity investment from years aa can } \\
\text { be used for generation in year a in the } \mathrm{CO}_{2} \\
\text { sector }\end{array}$ & $\{0,1\}$ \\
\hline USE_EL(t,a,aa) & $\begin{array}{l}\text { Flag if capacity investment from years aa can } \\
\text { be used for generation in year a in the } \\
\text { electricity sector }\end{array}$ & $\{0,1\}$ \\
\hline VC_CO2(n,s/i,a) & Variable costs for $\mathrm{CO}_{2}$ capture or storage & {$\left[\mathrm{k} \in / \mathrm{ktCO}_{2}\right]$} \\
\hline $\mathrm{VC}_{-}^{-} \mathrm{CO} 2-\mathrm{T}(\mathrm{n}, \mathrm{nn})$ & Variable costs for $\mathrm{CO}_{2}$ transport & {$\left[\mathrm{k} \in / \mathrm{ktCO}_{2}\right]$} \\
\hline VC_EL_T $\bar{T}(\mathrm{n}, \mathrm{nn})$ & Variable costs for electricity transport & {$[k \in / G W]$} \\
\hline$V C^{-} G(\bar{n}, t, a)$ & Variable generation costs w/o. or w/ capture & {$[\mathrm{k} \in / \mathrm{GWh}]$} \\
\hline
\end{tabular}

Table 4: List of parameters of the ELCO Model 


\subsection{The electricity sector}

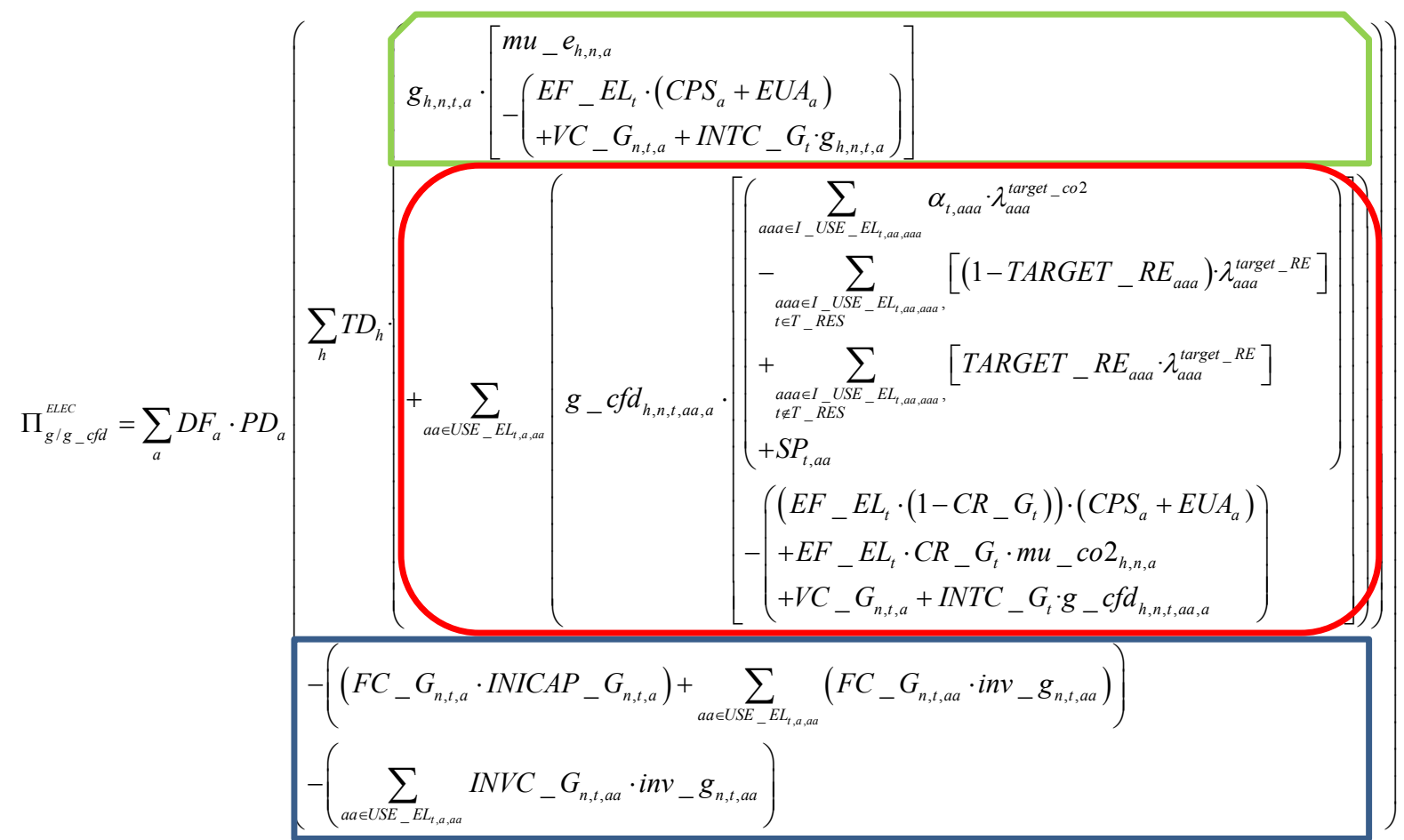

The ELCO model represents electricity generation from various technologies. Electricity generation is herby divided in the two subgroups $g_{h, n, t, a}$ and $g_{-} c f d_{h, n, t, a a, a} \cdot g_{h, n, t, a}$ comprise generation from all existing capacities and newly built carbon-intensive capacities from coal, gas OCGT and gas CCGT. $g_{-} c f d_{h, n, t, a a, a}$, on the other hand, include generation from newly constructed low-carbon generation capacities from PV, wind on/offshore, hydropower, biomass, CCTS coal/gas, and nuclear that are financed via the CfD scheme. The profit function for different technologies share the common component of fix costs $F C_{-} G_{n, t, a}$ and annualized investment costs INVC_ $G_{n, t, a}$ depending on the investments inv_ $g_{n, t, a}$ (lowest rectangular segment). The variable costs components and revenue differ: for $g$-type technologies (upper rectangle with upper flat corners) revenue is generated from sales on the electricity market receiving the electricity price $m u_{-} e_{h, n, a}$. The variable cost function comprise fuel and O\&M costs with a linear and a quadratic term (VC_G $G_{n, t, a}$ and INTC_G $\left.G_{t}\right)$. In addition $\mathrm{CO}_{2}$ costs are calculated based on the emission factor $E F \_E L_{t}$, multiplied with a combination of the EU-ETS $\mathrm{CO}_{2}$ certificate price $\left(E U A_{a}\right)$ and a carbon price support $\left(C P S_{a}\right.$ in case of a carbon floor price for the electricity sector). For g_cfd-type technologies (middle rectangle with rounded corners) revenue is generated from the new CfD scheme. The CfD strike price can be incorporated in two ways: It can either be set exogenously, differentiated by year of construction and technology type. Or the strike price is determined endogenously. In the latter case, it depends on the extent to which generation from the respective technology contributes to achieving the environmental goals (TARGET_CO2a and TARGET_RE $E_{a}$ ) and is incorporated in the dual variables of these constraints (see 2.2.1). This type also encounters additional variable cost components for possible $\mathrm{CO}_{2}$ infrastructure (transport and storage) which are passed via the dual variable $m u_{-} c 02_{h, n, a}$ and account for $\mathrm{CO}_{2}$ capture rates $C R \_G_{t}$. The technology specific quadratic cost term is interpreted as integration cost for increasing shares of $g \_c f d$-type generation. 


$$
\begin{aligned}
& 0 \leq \sum_{h} A V A I L_{h, n, t} \cdot T D_{h} \cdot \sum_{\substack{a a \in U S E \\
(t, t) \in O N L_{t, a, a s},}} i n L_{-} g_{n, t, a a} \cdot E M P S_{a a}
\end{aligned}
$$

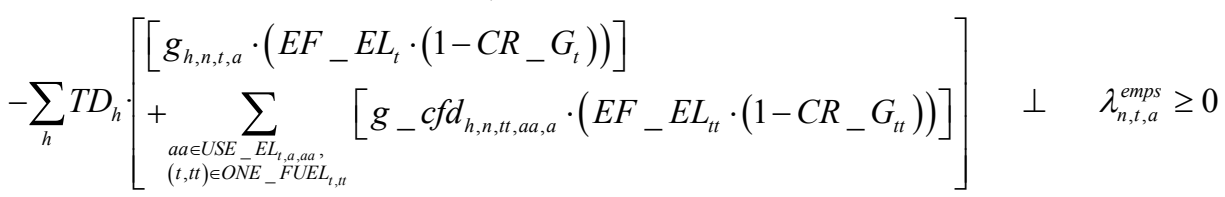

The individual players maximize their profit subject to several constraints. The EPS constraint (2) ensures that newly constructed generation capacities do not exceed the annual allowed $\mathrm{CO}_{2}$ emissions per $\mathrm{GW}$. The overall emissions are calculated as an annual fuel and site specific sum, allowing for combined accounting of new capacities with and without CCTS.

The generation capacity constraints (3) and (4) differ slightly for conventional generation technologies $g_{h, n, t, a}$ and newly constructed low-carbon technologies $g_{-} c f d_{h, n, t, a, a, a}$, as the calculation of currently available generation capacity differs for the two cases.

$0 \leq$ AVAIL $_{h, n, t} \cdot\left(I N I C A P_{-} G_{n, t, a}+\sum_{a a \in U S E_{-} E L_{t, a, a a}} i n v_{-} g_{n, t, a a}\right)-g_{h, n, t, a} \quad \perp \quad \lambda_{h, n, t, a}^{c a p} \geq 0$

$0 \leq$ AVAIL $_{h, n, t} \cdot i n v_{-} g_{n, t, a a}-g_{-} c f d_{h, n, t, a a, a} \perp \quad \lambda_{h, n, t, a a, a}^{c a p \_} g_{-} c f d \geq 0$

A diffusion constraint restricts the maximal annual investment depending on generation from previous periods and some initial starting value for new technologies.

$$
\begin{aligned}
& 0 \leq\left(S T A R T_{-} G_{t} \cdot \frac{\sum_{h, n} \text { AVAIL }_{h, n, t} \cdot T D_{h}}{\# \text { of nodes }}+\left[\sum_{h, n, a a} T D_{h} \cdot\left(g_{-} c f d_{h, n, t, a a, a-1}+g_{-} c f d_{h, n, t, a a, a-2}\right)\right]\right) \cdot D I F F_{-} G_{t} \\
& -\sum_{h, n, a a} T D_{h} \cdot g_{-} c f d_{h, n, t, a a, a} \perp \quad \lambda_{t, a}^{\text {diff }-g} \geq 0
\end{aligned}
$$

Another constraint limits the overall investment depending on a technology-specific maximal potential for each node.

$$
0 \leq M A X_{-} I N V_{n, t}-\sum_{a a \in U S E_{-} E L_{t, a, a a}} i n v_{-} g_{n, t, a a} \quad \perp \quad \lambda_{n, t, a}^{p o t} g
$$

\subsubsection{Shared environmental constraints for the electricity sector}

All players in the electricity sector have to respect shared environmental constraints: An annual $\mathrm{CO}_{2}$ target guarantees that the annual dispatch is lower or equal an exogenously set $\mathrm{CO}_{2}$ reduction path.

$$
0 \leq P D_{a} \cdot \sum_{h, n, t} T D_{h} \cdot\left[\left(g_{h, n, t, a}+\sum_{a a \in U S E_{-} E L_{t, a, a a}} g_{-} c f d_{h, n, t, a a, a}\right) \cdot \alpha_{t, a}\right] \quad \perp \quad \lambda_{a}^{\text {target_co2 }} \geq 0
$$

$A L P H A_{t, a}$ corresponds to the marginal contribution of the respective technology to the targeted $\mathrm{CO}_{2}$ intensity for a particular year. It is positive for low-carbon technologies while having negative values for conventional generation. 
$\alpha_{t, a}=\frac{C O 2_{-} T A R G E T_{a} \cdot R E F_{-} C O 2}{\sum_{h, n} D_{h, n, a} \cdot T D_{h}}-\left(1-C R_{-} G_{t}\right) \cdot E F_{-} E L_{t}$

National renewable targets setting a minimum share of renewable generation are implemented in an additional renewable constraint in some scenarios. This constraint, however, is deactivated in the scenario analyzed in this paper.

$0 \leq P D_{a} \cdot \sum_{h, n} T D_{h} \cdot\left[\begin{array}{l}\sum_{\substack{a \in \in U S E \\ t \in T_{-} R E S}} g_{L, a, a,}, c f d_{h, n, t, a a, a}+R E S_{-} O L D_{h, n, a} \\ -R E_{-} T A R G E T_{a} \cdot \sum_{h, n} d_{h, n, a}\end{array}\right] \perp \quad \lambda_{a}^{\text {target } R E} \geq 0$

\subsection{The electricity transportation utility}

The objective function of the electricity transportation utility is shown in the following equation: The sum of variable costs $V C_{-} E L_{-} T_{n, n n}$ and annualized investment costs INVC_EL_ $T_{n, n n}$ equalize the hourly electricity price difference between two nodes in case of no line congestion. Possible congestion rents are kept by the transportation utility as profit. Electricity is treated as a normal transport commodity ignoring Kirchhoff's $2^{\text {nd }}$ law as network congestion is not the focus of the ELCO model.

$$
\Pi^{T S O_{-} E}=\sum_{a} D F_{a} \cdot P D_{a} \cdot \sum_{n, n n}\left[\begin{array}{l}
-\sum_{h} T D_{h} \cdot\left(\begin{array}{l}
\left(m u_{-} e_{h, n, a}-m u_{-} e_{h, n n, a}\right) \cdot e l \_t_{h, n, n n, a} \\
+V C_{-} E L_{-} T_{n, n n} \cdot e l_{-} t_{h, n, n n, a}
\end{array}\right) \\
-\sum_{a a<a}\left(I N V C_{-} E L_{-} T_{n, n n} \cdot i n v_{-} e l_{-} t_{n, n n, a}\right)
\end{array}\right]
$$

The electricity utility maximizes its profits subject to the following line capacity constraint:

$$
\begin{aligned}
& 0 \leq I N I C A P_{-} E L_{-} T_{n, n n}+\sum_{a a<a}\left(A D J_{-} E L_{n, n n} \cdot i n v_{-} e l_{-} t_{n, n n, a a}+A D J_{-} E L_{n n, n} \cdot i n v_{-} e l_{-} t_{n n, n, a a}\right) \\
& -e l_{-} t_{h, n, n n, a} \perp \quad \lambda_{h, n, n n, a}^{c a p_{-} e l^{t}} \geq 0
\end{aligned}
$$

\subsection{The industry sector}

The industry is being represented by the two sectors $i$ : Iron and Steel as well as cement which are most likely to use $\mathrm{CO}_{2}$ capture as mitigation option. The objective function of the industry sectors is limited to the abatement costs linked to exogenously given historic $\mathrm{CO}_{2}$ emissions. They include the option of either paying the EUA $A_{a}$ or investing into the CCTS technology with its variable costs $V C_{-} C O 2_{n, i, a}$, fix costs $F C_{-} C O 2_{n, i, a}$ and annualized investment costs INVC_CO2 $2_{n, i, a}$. The additional costs for a possible $\mathrm{CO}_{2}$ infrastructure (transport and storage) are being passed on from the downstream $\mathrm{CO}_{2}$ sector via the dual variable mu_co $2_{h, n, a}$. 


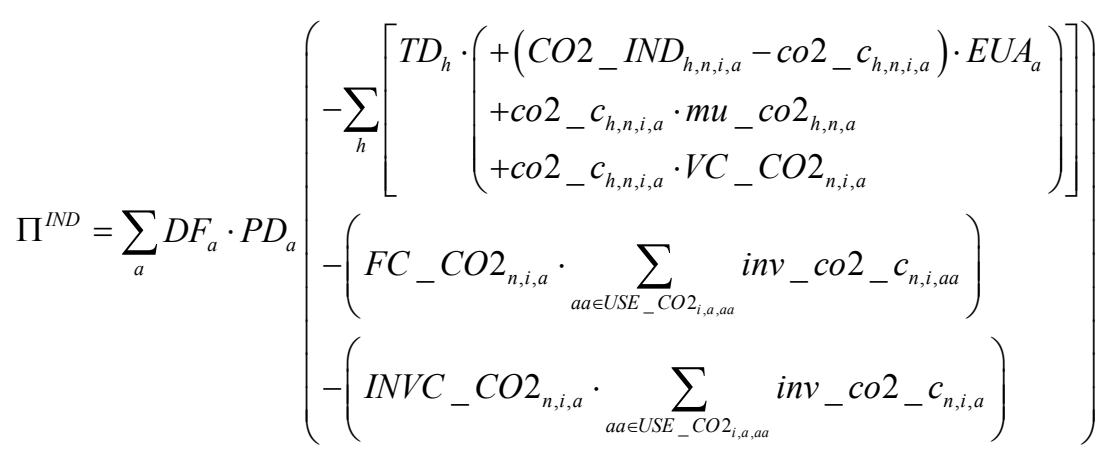

The industry sector maximizes its objective function subject to similar constraints as the electricity sector. A diffusion constraint restricts the maximal annual investment depending on previous investments.

$0 \leq\left(S T A R T \_C O 2_{i}+\sum_{n} \sum_{a a<a} i n v_{-} c 02_{-} c_{n, i, a a}\right) \cdot D I F F_{-} C O 2_{i}-\sum_{n} i n v_{-} c o 2_{-} c_{n, i, a} \quad \perp \quad \lambda_{i, a}^{d i f f-c o 2_{-} c} \geq 0$

The annual capturing quantity is restricted by the amount of previous investments as well as the overall maximal capturing quantity per node and technology.

$$
\begin{aligned}
& 0 \leq \sum_{a a \in U S E_{-} C O 2_{i, a, a a}} i n v_{-} C O 2_{n, i, a a} \cdot C R_{-} I N D_{i}-c o 2_{-} c_{h, n, i, a} \perp \quad \lambda_{h, n, \bar{i}, a}^{c a 2_{-} c} \geq 0 \\
& 0 \leq C O 2_{-} I N D_{h, n, i, a} \cdot C R_{-} I N D_{i}-c 02_{-} c_{h, n, i, a} \perp \quad \lambda_{h, n, i, a}^{\max i n d} \geq 0
\end{aligned}
$$

\subsection{The $\mathrm{CO}_{2}$ transportation utility}

The $\mathrm{CO}_{2}$ transportation utility maximizes its profit show in Equation (16). The sum of variable costs VC_CO2_ $T_{n, n n}$ and annualized investment costs INVC_CO2 $2_{n, n n}$ equalize the difference between the dual prices between two nodes.

$$
\Pi^{T S O_{-} C O 2}=\sum_{a} D F_{a} \cdot P D_{a} \cdot \sum_{n, n n}\left[\begin{array}{l}
-\sum_{h} T D_{h} \cdot\left(\begin{array}{l}
\left(m u_{-} c o 2_{h, n, a}-m u_{-} c o 2_{h, n n, a}\right) \cdot c o 2_{-} t_{h, n, n n, a} \\
+V C_{-} C O 2_{-} T_{n, n n} \cdot c o 2_{-} t_{h, n, n n, a}
\end{array}\right) \\
-\sum_{a a<a}\left(I N V C_{-} C O 2_{-} T_{n, n n} \cdot i n v_{-} c o 2_{-} t_{n, n n, a}\right)
\end{array}\right]
$$

A pipeline capacity constraint restricts $\mathrm{CO}_{2}$ transport:

$$
\begin{aligned}
0 \leq & \text { INICAP_CO2_ } T_{n, n n}+\sum_{a a<a}\left(\begin{array}{l}
A D J_{-} C O 2_{n, n n} \cdot i n v_{-} c o 2_{-} t_{n, n n, a a} \\
+A D J_{-} C O 2_{n n, n} \cdot i n v_{-} c o 2_{-} t_{n n, n, a a}
\end{array}\right)-c o 2_{-} t_{h, n, n n, a} \\
& \perp \quad \lambda_{h, n, n n, a}^{c a p}{ }^{c a c o} \geq 0
\end{aligned}
$$

\subsection{The storage sector}

Saline aquifers, depleted oil and gas fields (DOGF) and fields with the opportunity for $\mathrm{CO}_{2^{-}}$ EOR are identified as possible storage locations $s$. The objective function of the storage operator represents the abatement costs linked to the underground storage of $\mathrm{CO}_{2}$. For $\mathrm{CO}_{2}$ EOR sites it includes the option of returns received from oil sales at oil price OILPRICE $E_{a}$. The storage costs consist of the variable costs $V C_{-} C O 2_{n, s, a}$, a quadratic cost term INTC_S $S_{t}$, fix 
costs $F C \_C O 2_{n, s, a}$ and annualized investment costs INVC_CO2 $2_{n, s, a}$. The dual variable $m u \_c o 2_{h, n, a}$ is used to pass on the overall storage costs (or in case of $\mathrm{CO}_{2}$-EOR also possible returns) to the $\mathrm{CO}_{2}$ transport sector.

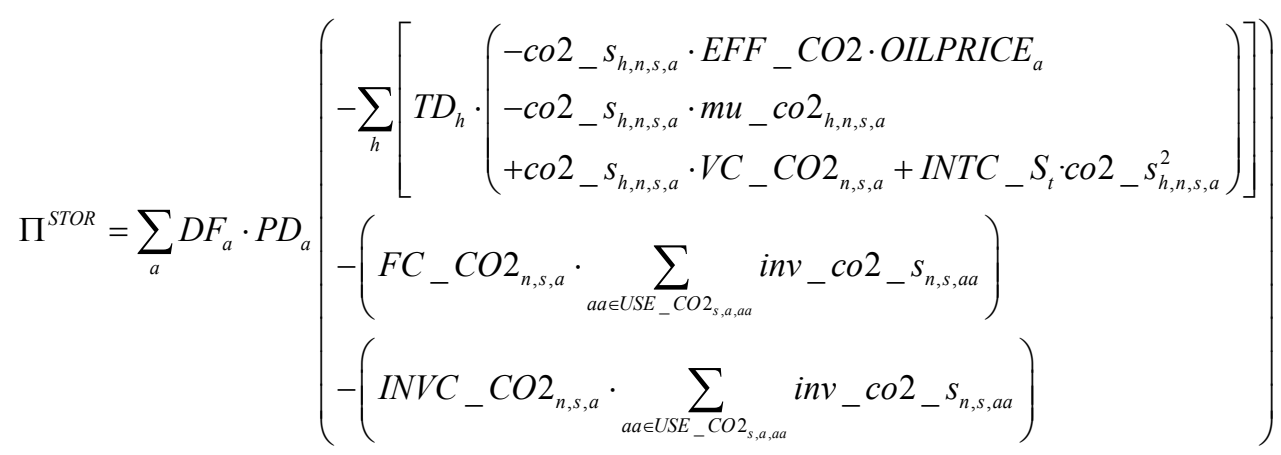

Storage entities maximize their objective functions subject to a respective diffusion constraint which limits their maximal annual investment based on previous investments.

$$
0 \leq\left(S T A R T_{-} C O 2_{s}+\sum_{n} \sum_{a a<a} i n v_{-} c 02_{-} s_{n, s, a a}\right) \cdot D I F F_{-} C O 2_{s}-\sum_{n} i n v_{-} c 02_{-} s_{n, s, a} \quad \perp \quad \lambda_{s, a}^{d i f f c o 2_{-} s} \geq 0
$$

Further constraints restrict the annual storage quantities based on prior investments as well as the overall maximal storage quantity per site and technology.

$$
\begin{aligned}
& 0 \leq \sum_{a a \in U S E_{-} C O 2_{s, a, a a}} i n v_{-} c 02_{-} s_{n,, s a}-c o 2_{-} s_{h, n, s, a} \perp \quad \lambda_{h, n, s, a}^{c a p_{-} c o 2_{-} s} \geq 0 \\
& 0 \leq M A X_{-} S T O R_{n, s}-\sum_{h}\left(T D_{h} \cdot \sum_{a a \leq a} P D_{a a} \cdot c 02_{-} s_{h, n, s, a a}\right) \perp \quad \lambda_{n, s, a}^{\max s t o r} \geq 0
\end{aligned}
$$

\subsection{Market clearing conditions across all sectors}

Three market clearing conditions connect the different sites (represented as nodes) and sectors in the ELCO model: The first two represent the energy balance, while the third balances $\mathrm{CO}_{2}$ flows. With the introduction of the CfD scheme, the electricity market is fragmented: Technologies not supported by the CfD scheme market their generation to serve residual demand that remains after subtracting supply from CfD supported technologies shown in Equation (22). The free dual variable $m u_{-} e_{h, n, a}$ of this equation corresponds to the price observed at the electricity wholesale market. By contrast, CfD technologies do not observe any feedback between their generation and market demand, just like in reality. Therefore, an additional curtailment constraint needs to be introduced in Equation (23), that limits total generation to meet the total demand.

$$
\begin{aligned}
& 0=\sum_{t}\left(g_{h, n, t, a}+\sum_{a a \in U S E_{-} E L_{L, a, a a}} g_{-} c f d_{h, n, t, a a, a}\right)+\sum_{n n} e l_{-} t_{h, n n, n, a}-\sum_{n n} e l_{-} t_{h, n, n n, a}-\left(D_{h, n, a}-R E S_{-} O L D_{h, n, a}\right) \\
& \quad m u_{-} e_{h, n, a}(f r e e) \quad \forall h, n, a \\
& 0 \leq \sum_{n}\left(D_{h, n, a}-R E S \_O L D_{h, n, a}\right)-\sum_{n} \sum_{t}\left(g_{h, n, t, a}+\sum_{a a \in U S E_{-} E L_{t, a, a a}} g_{-} c f d_{h, n, t, a a, a}\right) \perp \quad \lambda_{n, a}^{\text {curt } g} \geq 0
\end{aligned}
$$


The third market clearing is the $\mathrm{CO}_{2}$ flow balance with its free dual variable $m u_{-} c \mathrm{co} 2_{h, n, a}$.

$$
\begin{aligned}
& 0=\sum_{n n} c o 2_{-} t_{h, n, n, a}+\sum_{s} c o 2_{-} s_{h, n, s, a}-\sum_{i} c o 2_{-} c_{h, n, i, a}-\sum_{t}\left(\sum_{a a \in U S E_{-} E L_{t, a, a a}} g-c f d_{h, n, t, a a, a} \cdot E F_{t} \cdot C R_{-} G_{t}\right) \\
& -\sum_{n n} c 02_{-} t_{h, n n, n, a} \quad m u_{-} c o 2_{h, n, a}(\text { free }) \quad \forall h, n, a
\end{aligned}
$$

\section{Case study: the UK Electricity Market Reform}

The UK energy and climate policy used to be subject to a significant dichotomy between its policy targets and reality. Despite of fixed goals on final energy consumption from renewables (15\% in 2020) and binding five-year carbon reduction targets towards a $80 \%$ reduction by 2050 , the current energy policy framework was lacking instruments to incentivize investments that are necessary to achieve these goals. In addition, up to $20 \mathrm{GW}$ of mostly coal fired generation have exceeded 40 years of age in the year 2015 and are either to be decommissioned or in need of retrofit investments ${ }^{4}$. The upcoming decade therefore becomes vital for a future decarbonized electricity market to prevent stranded investments in carbon intensive power plants. The UK government decided to undertake a major restructuring of its energy policy framework, called Electricity Market Reform (EMR) (The Parliament of Great Britain 2013). The EMR introduces four main policies to support low-carbon technologies: Contracts for Differences (CfD), Carbon Floor Price (CFP), Emissions Performance Standards (EPS) and a Capacity Market (CM).

These instruments constitute a major reform to the previous framework of the UK electricity market which was characterized by a high competitiveness and low market concentration (DECC 2014b). Thus, its effects have been controversially discussed (e.g. by Pollitt und Haney 2013; Chawla und Pollitt 2013). Some critics question the effect the reform might have on the UK electricity market and in particular on the future of low-carbon technologies. The future generation mix will be mostly determined by the government through long-term contracts with little ability to react quickly to future changes. Major risks include possible welfare losses as well as possible breached climate targets due to stranded investments in carbon intensive power plants (a topic examined by Johnson et al. (2015) on a global level). This calls for additional research on low-carbon technologies in the UK. Chalmers et al. (2013) summarize the findings of the two-year UKERC research project on the implementation of CCTS in the UK. To our best knowledge, however, there is no model that evaluates the effects of the UK-EMR on the UK electricity market as well as on the overall CCTS value chain including also the main industrial $\mathrm{CO}_{2}$ emitters.

\footnotetext{
${ }^{4}$ UK government has announced that there "will be a consultation in spring 2016 on when to close all unabated coal-fired power stations. The consultation will set out proposals to close unabated coal-fired power stations by 2025 - and restrict use from 2023" (see https://www.gov.uk/government/uploads/system/uploads/attachment_data/file/477703/ MktAnnct.pdf [accessed: 18.11.2015]).
} 
The following section describes the UK-EMR and the policy measures which are included in the ELCO model. ${ }^{5}$ The used data set and results of this case study are afterwards discussed in the sections 3.2 and 3.3 .

\subsection{Describing the instruments: Contracts for Differences, Carbon Price Floor, and Emissions Performance Standard}

Contracts for Differences (CfD) were tied in the UK Energy Bill in 2013. They consist of a strike price for different low-carbon technologies resembling a fixed feed-in tariff. Generators take part in the normal electricity market but receive top-up payments from the government if the achieved prices are lower than the strike price. The government, on the other hand, receives equivalent payments from the generator if the market price exceeds the strike price. $\mathrm{CfD}$ and inherent strike prices are fixed for the duration of the contract. The long-term target of the CfD scheme is to find the most competitive carbon neutral technologies. In the short run, strike price levels are decided on in a technology-specific administrative negotiation process. In the long run, it is envisioned to determine a common strike price via a technology-neutral auction.

The UK government hopes that CfD enhance future investments as feed-in tariffs reduce the risk of market prices and gives incentives for cost reductions. Technologies that should be supported through CfD are various kinds of renewables (e.g. on-/offshore wind, PV, tidal, etc.) but also CCTS and nuclear. International dissent exists especially for the latter. Critics argue that a CfD for nuclear energy resembles an illegal subsidy tailored for the newly planned "Hinkley Point" project. The European Commission (EC) regulation requires implementation for an entire technology and accessibility for all possible investors. The nuclear sector, on the other hand, is due to its technology and safety specifics only open for a limited number of actors. The EC, however, decided in favour of the project after a formal investigation in October 2014, which might also have an effect on nuclear policies in other countries (Černoch and Zapletalová 2015).

The UK introduced a Carbon Price Floor (CPF) of $16 £ / \mathrm{tCO}_{2}$ (around $20 € / \mathrm{tCO}_{2}$ ) for the electricity generators in 2013 to reduce uncertainty for investors. The CPF consists of the EU-ETS $\mathrm{CO}_{2}$ price and a variable climate change levy on top (carbon price support (CPS)). Forecasting errors in predicting the price of EU-ETS two years ahead can lead to distortions between the targeted and the final CPF. The climate change levy actually already exists since 2001, but the electricity sector used to be exempted from it. In 2013, the levy is expected to generate around $£ 1$ bn in the year 2013 (Ares 2014).

Initially, the CPF was planned to be gradually increasing to reach a target price of $30 £ / \mathrm{tCO}$ (around $38 € / \mathrm{tCO}_{2}$ ) in 2020 and $70 £ / \mathrm{tCO}_{2}$ (around $88 € / \mathrm{tCO}_{2}$ ) in 2030. A constantly rising minimum price should ensure increasing runtimes for low-carbon technologies such as renewables, nuclear and CCTS as fossil based electricity generation becomes more expansive due to their $\mathrm{CO}_{2}$ emissions. The British minister for finance, however, announced in March 2014 that the CPF will be frozen at a level of $18 £ / \mathrm{tCO}_{2}$ (around $23 € / \mathrm{tCO}_{2}$ ) until 2019/20 (Osborne 2014). The reason for this decision was the increasing discrepancy

\footnotetext{
${ }^{5}$ The specifics of a possible capacity market in the UK are not clear yet and were therefore not included in this case study.
} 
between the CPF and the EU-ETS $\mathrm{CO}_{2}$ emission price, lowering the competitiveness of British firms. It is yet unclear, how the CPF will evolve after 2020; depending probably largely on the effect of the upcoming structural reform of the EU-ETS. The CPS only has an effect on the British electricity sector. Neither is the combustion of natural gas for heating or cooking nor are electricity imports from neighboring countries affected by this instrument. The latter is also the main reason why the CPS has not been implemented in Northern Ireland which is part of the single electricity market in Ireland. (Pollitt and Haney 2013)

Another instrument implemented in the Energy Bill is the $\mathrm{CO}_{2}$ Emissions Performance Standard (EPS) (The Parliament of Great Britain 2013). It limits the maximal annual $\mathrm{CO}_{2}$ emission of newly built or retrofitted electricity units to the ones of an average gas-fired power plant without carbon capture. Plants with higher carbon intensities like coal-fired units either have to reduce their load factor or install capture facilities for parts of their emissions. The EPS for a unit can be calculated by multiplying its capacity with $450 \mathrm{gCO}_{2} / \mathrm{kWh}$ times $7,446 \mathrm{~h}$ (equivalent to a 0.85 load factor and $8,760 \mathrm{~h}$ per year). This results in an annual $\mathrm{CO}_{2}$ budget of $3,350 \mathrm{tCO}_{2} / \mathrm{MW}$, restricting a coal-fired unit with emissions of $750 \mathrm{~g} / \mathrm{kWh}$ to a maximal load factor of 0.5 or $4,470 \mathrm{~h}$ per year. The goal of this regulation is to foster investment in new gas power plants as well as power plants with capturing units. Power plants with capture units are additionally exempted from EPS for the first three years of operation to optimize their production cycles. Special exemptions exist for biomass emissions of plants below $50 \mathrm{MW}$ related to heat production and in the case of temporary energy shortage.

\subsection{Data input}

Electricity generation capacities as well as data for investment cost, variable cost, fixed cost, availability and life time assumptions are taken from DECC (2013a; 2014a). We assume a linear cost reduction over time for the investment cost according to Schröder et al. (2013); variable and fixed cost remain constant. The costs are independent from power plant location; but availabilities of renewables do vary. Industrial $\mathrm{CO}_{2}$ emissions and their location are taken from studies concentrating on CCTS adoption in the UK industry sector (Element Energy et al. 2014; Houses of Parliament 2012). Capturing costs in the industry sector as well as costs for $\mathrm{CO}_{2}$ storage and $\mathrm{CO}_{2}$-EOR application are taken from Mendelevitch (2014). The fixed costs are included in the variable capturing costs.

The simplified representation used for this case study consists

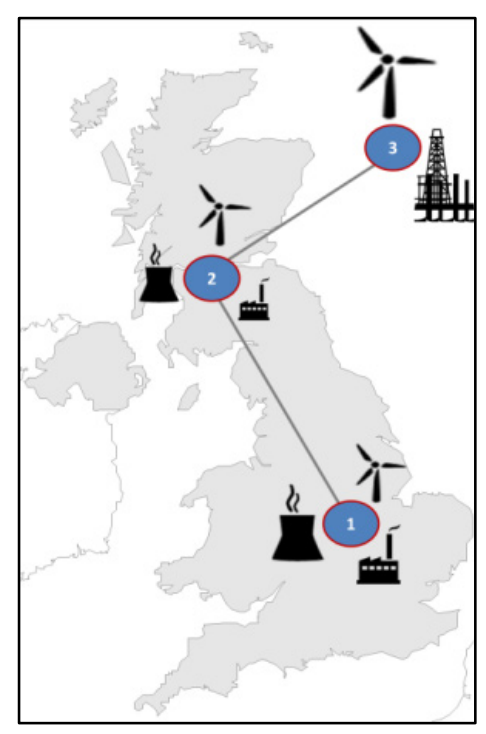

Figure 1: Simplified network of three nodes (see Figure 1). Node 1 and 2 represent the Northern and Southern part of the UK with their power plants and industrial facilities. A third offshore node resembles possible locations for offshore wind parks as well as $\mathrm{CO}_{2}$ storage with and without $\mathrm{CO}_{2}$-EOR in the North Sea. We assume electricity and $\mathrm{CO}_{2}$ pipeline connections between node 1 and 2 as well as between node 2 and node 3 . We assume a simplified electricity grid neglecting congestion between nodes in this scenario. In addition, no exchange with the neighboring 
countries is allowed. $\mathrm{CO}_{2}$ pipelines can endogenously be constructed between adjacent nodes.

The CPF is assumed to remain constant at $18 £ / \mathrm{tCO}_{2}$ (around $23 € / \mathrm{tCO}_{2}$ ) until 2020. We assume the $\mathrm{CO}_{2}$ price to increase due to the effects of the structural reform of the EU-ETS. CPF and $\mathrm{CO}_{2}$ price are thus assumed to have the same level from 2030 onwards, rising linearly from $€ 35$ in 2030 to $€ 80$ in 2050 . We include the given price projections for the strike prices in 2015 and 2020 DECC (2013b). These technology specific differences will be linearly reduced until 2030. Starting from 2030 all technologies under the CfD will be given the same financial support via an endogenous auctioning system. The EPS is set at a level of $450 \mathrm{~g} / \mathrm{kWh}$. An annual $\mathrm{CO}_{2}$ emissions reduction of $1 \%$ in the electricity sector is implemented leading to $90 \%$ emissions reduction in 2050 compared to 1990 . No specific RES target is set. The discount rate is $5 \%$ for all players. The oil price is expected to remain at its current level of $65 € / \mathrm{bbl}$.

The annual load duration curve of UK is approximated by five type hours, assuming a demand reduction of $20 \%$ till 2050 (base year 2015). This simplification does not allow for demand shifting nor energy storage in between type hours. $\mathrm{CO}_{2}$ emissions from industrial sources are assumed to decline by $40 \%$ until 2050 . The lifetime of the existing power plant fleet varies by technology between 25 (most renewables), 40 (gas) and 50 (coal, nuclear, and hydro) years.

\subsection{Case study results}

This simplified base case was created to show the characteristics and features of the ELCO model. Its results should not be over-interpreted but give an idea of the potential of the model, once its complete data set is calibrated.

The implementation of the various policy measures leads to a diversified electricity portfolio in 2050: with no specific RES target in place, renewables account for $46 \%$ of generation, gas $(26 \%)$, nuclear $(15 \%)$, and CCTS $(13 \%)$. The majority of the investments in new renewable capacity happen before 2030 . Less favorable regional potentials and technologies such as $\mathrm{PV}$ are only used in later periods. The implemented incentive mechanism is comparable to an auctioning system of "uniform pricing" where the last bidder sets the price. The average payments for low-carbon technologies are in the range of 80 to $110 € / \mathrm{MWh}$ but depend strongly on the assumptions for learning curves and technology potentials. Different allocation mechanisms such as "pay as bid" might lower the overall system costs.

The share of coal-fired energy production is sharply reduced from 39\% in 2015 to $0 \%$ in 2030 due to a phasing-out of the existing capacities (see Figure 2). New investments in fossil capacities occur for gas-fired CCGT plants, which are built from 2030 onwards. EPS hinders the construction of any new coal-fired power plant. Sensitivity analysis shows that a change of its current level of $450 \mathrm{~g} / \mathrm{kWh}$ in the range of $400-500 \mathrm{~g} / \mathrm{kWh}$ has only little effect: Gas-fired power plants would still be allowed sufficient run-time hours while coal-fired plants remain strongly constrained. The overall capacity of nuclear power plants is slightly reduced over time. ${ }^{6}$ The share of renewables in the system grows continuously from $20 \%$ in 2015 to $30 \%$

6 This is influenced through the diffusion constraint that limits the maximal annual construction, esp. in early periods. 
in 2030 and $46 \%$ in 2050 . Wind off- (41\% in 2050) and onshore (25\% in 2050) are the main renewable energy sources followed by hydro and biomass (together $27 \%$ in 2050).

$\mathrm{CO}_{2}$-EOR creates additional returns for CCTS deployment through oil sales. These profits trigger investments in CCTS regardless of additional incentives from the energy market. The potential for $\mathrm{CO}_{2}$-EOR is limited and will be used to its full extent until 2050. The maximum share of CCTS in the energy mix is $16 \%$ in 2045 . The combination of assumed ETS and oil price also triggers CCTS deployment in the industry sector from 2020 onwards (see Figure 3 ). The industrial $\mathrm{CO}_{2}$ capture rate, contrary to the electricity sector, is constant over all type hours. The storage process requires a constant injection pressure, especially when connected to a $\mathrm{CO}_{2}$-EOR operation. This shows the need for intermediate $\mathrm{CO}_{2}$ storage to enable a continuous storage procedure and should be more closely examined in further studies. From 2030 onwards, emissions in the industrial sector are captured with the maximum possible capture rate of $90 \%$. The usage of saline aquifers as well as depleted oil and gas fields is not beneficial assuming a $\mathrm{CO}_{2}$ certificate price of $80 € / \mathrm{tCO}_{2}$ in 2050 .

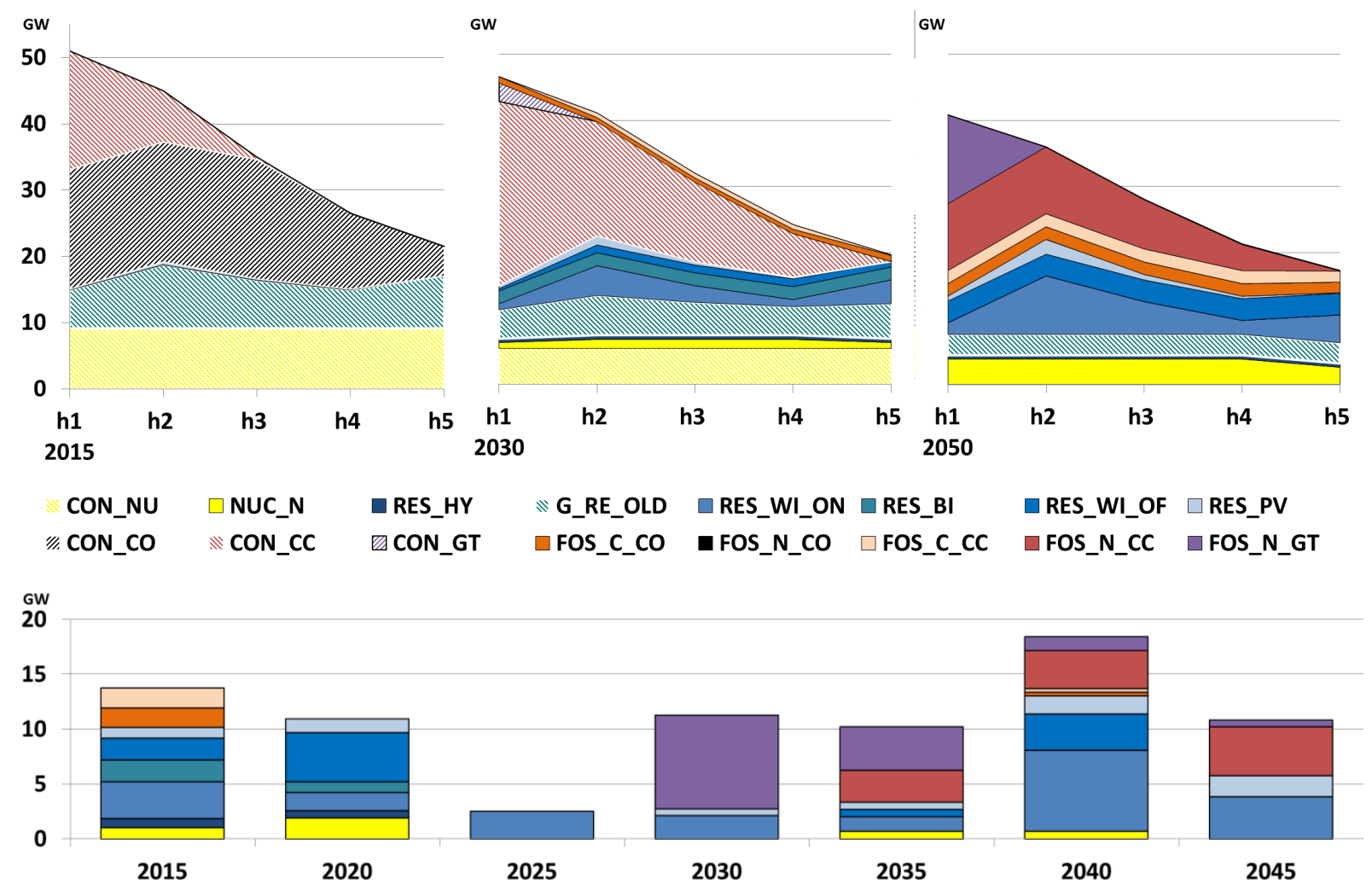

Figure 2: Electricity generation (top) and power plant investment (bottom) from 20152050.

Source: Own modeling results with the ELCO model. 


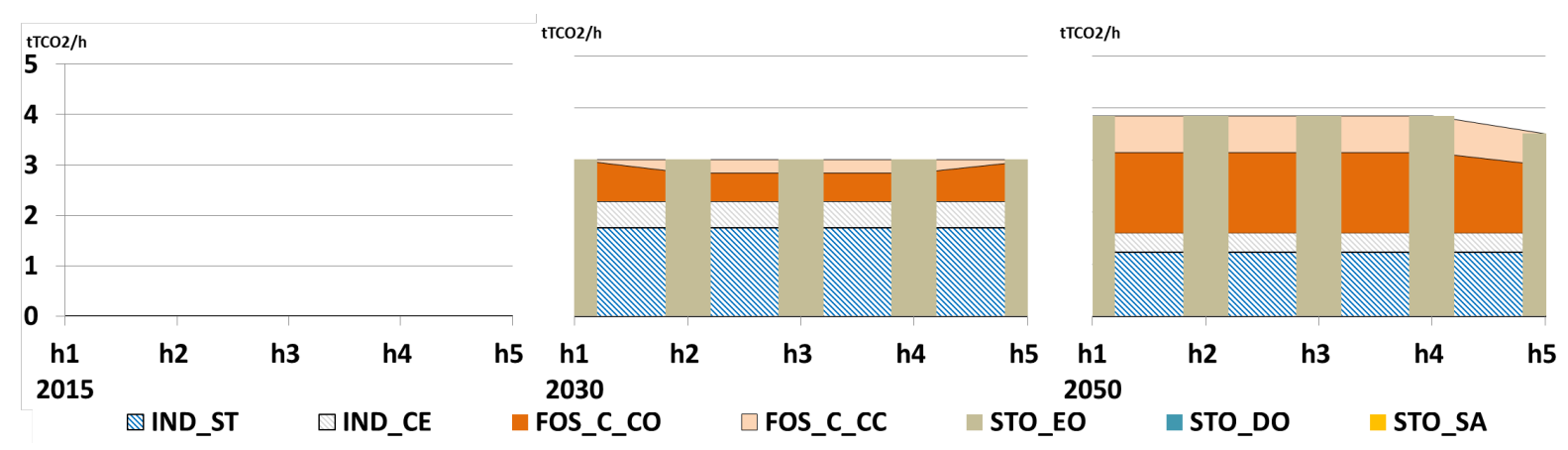

Figure 3: $\mathrm{CO}_{2}$ capture by electricity and industrial sector (area) and $\mathrm{CO}_{2}$ storage (bars) in 2015, 2030 and 2050

Source: Own modeling results with the ELCO model.

\section{Conclusion}

This paper presents a general electricity- $\mathrm{CO}_{2}$ modeling framework (ELCO model) that is able to simulate interactions of the energy-only market with different forms for national policy measures as well as a full representation of the carbon capture, transport, and storage (CCTS) chain. Different measures included in the model are feed-in tariffs, a minimum $\mathrm{CO}_{2}$ price and Emissions Performance Standards (EPS). Additionally, the model includes large point industrial emitters from the iron and steel as well as cement sector that might also invest in carbon capture facilities, increasing scarcity for $\mathrm{CO}_{2}$ storage. Therefore, the modeling framework mimics the typical issues encountered in coal-based electricity systems that are now entering into transition to a low-carbon generation base. The model can be used to examine the effects of different envisioned policy measures and evaluate policy trade-offs.

This paper is used to describe the different features and potentials of the ELCO model. Such characteristics can easily be examined with a simplified model, even though its quantitative results should not be over-interpreted. As further development steps we need to test the robustness of the equilibrium results with sensitivity analysis while increasing the regional and time resolution of the model.

The results of the case study on the UK electricity market reform (EMR) present a show case of the model framework. It incorporates the unique combination of a fully represented CCTS infrastructure and a detailed representation of the electricity sector in UK. The instruments of the UK EMR, like EPS, CfD and CPF are integrated into the framework. Also we take into account demand variation in type hours, the availability of more and less favorable locations for RES and limits for their annual diffusion. The model is driven by a $\mathrm{CO}_{2}$ target and an optional RES target.

The next steps are to compare the costs of different incentive schemes and to analyze their effects on the deployment of different low-carbon technologies, with a special focus on CCTS with and without the option for $\mathrm{CO}_{2}$-enhanced oil recovery $\left(\mathrm{CO}_{2}-\mathrm{EOR}\right)$. The role of industry CCTS needs to be further considered in this context. Additionally, we plan to study the feedback effects between the CfD scheme and the electricity price, and investigate the incentives of the government which acts along the three pillars of energy policy: costefficiency, sustainability and security; in a two-level setting. This also includes calculating the system integration costs of low-carbon technologies. A more detailed representation of the electricity transmission system operator (TSO) as market organizer helps doing so by 
separating financial and physical flows. The TSO is on the one hand responsible to guarantee supply meeting demand at any time and on the other hand reimburses CfD technologies for curtailment. At a later stage, we want to use the model for more realistic case studies to draw conclusions and possible policy recommendations for low-carbon support schemes in the UK as well as in other countries.

\section{Acknowledgement}

The first draft of the model was developed during a research stay at the International Institute for Applied System Analysis (IIIASA) in Laxenburg, Austria. We want to thank all members of the Energy department and in particular Nils Johnson for numerous fruitful discussions and helpful inputs during these months. Additional thanks goes to our colleagues at DIW Berlin and TU Berlin Claudia Kemfert, Christian von Hirschhausen, Franziska Holz, Daniel Huppmann, and Alexander Zerrahn for their discussions, critiques, and comments. The usual disclaimer applies. 


\section{References}

ABB Asea Brown Boveri Ltd. 2011. 'ABB HVDC Reference Projects.' Zurich, Switzerland. http://www.abb.de/industries/ge/9AAF400191.aspx?country=DE.

Ainger, D., S. Argent, and S. Haszeldine. 2010. 'Feasibility Study for Europe-Wide $\mathrm{CO}_{2}$ Infrastructures'. Study for the European Commission Directorate-General Energy Issue Rev.00 TREN/372 -1/C3/2009. Leeds, UK: Ove Arup \& Partners Limited.

Allevi, E., F. Bonenti, and G. Oggioni. 2013. 'Compelementarity Models for Restructured Electricity Markets under Environmental Regulation'. Statistica \& Applicazioni; Special Issue 2013. Italy.

Ares, Elena. 2014. 'Carbon Price Floor'. London, UK: House of Commons Library. Ilafsltuberlin.delunitsIFak_VIIIwiplsharelliteratur|Ares_2014-Carbon_Price_Floor_SN_SC_5927.pdf.

Bentham, Michele. 2006. 'An Assessment of Carbon Sequestration Potential in the UK - Southern North Sea Case Study'. Working Paper 85. Nottingham and Keyworth, UK: Tyndall Centre for Climate Change Research and British Geological Survey.

Bentham, M. S., K. L. Kirk, and J. Wiliams. 2008. 'Basin-by-Basin Analysis of $\mathrm{CO}_{2}$ Storage Potential of All-Island Ireland'. Sustainable Energy and Geophysical Surveys Programm Commissioned Report CR/08/036. UK: British Geological Survey.

Brook, M., K. Shaw, C. Vincent, and S. Holloway. 2009. 'Gestco Case Study 2a-1: Storage Potential of the Bunter Sandstone in the UK Sector of the Southern North Sea and the Adjacent Onshore Area of Eastern England'. Keyworth, Nottingham, UK: Sustainable Energy and Geophysical Surveys Programm. Commissioned Report CR/03/154.

Bundesregierung. 2011. Energy Line Extension Act - Energieleitungsausbaugesetz EnLAG. Bundesministerium Für Wirtschaft (BMWi), Berlin, Germany.

Capros, Pantelis, L. Mantzos, D. Kolokotsas, N. Ioannou, T. Georgakopoulos, A. Filippopoulitis, and Y. Antoniou. 1998. 'The PRIMES Energy System Model-reference Manual'. National Technical University of Athens, Greece.

Černoch, Filip, and Veronika Zapletalová. 2015. 'Hinkley Point C: A New Chance for Nuclear Power Plant Construction in Central Europe?' Energy Policy 83 (August): 165-68. doi:10.1016/j.enpol.2015.04.002.

Chalmers, Hannah, Jon Gibbins, Rob Gross, Stuart Haszeldine, Phil Heptonstall, Florian Kern, Nils Markusson, Peter Pearson, Jim Watson, and Mark Winskel. 2013. 'Analysing Uncertainties for CCS: From Historical Analogues to Future Deployment Pathways in the UK'. Energy Procedia, GHGT-11, 37: 7668-79. doi:10.1016/j.egypro.2013.06.712.

Chawla, Mallika, and Michael Pollitt. 2013. 'Global Trends in Electricity Transmission System Operation: Where Does the Future Lie?' The Electricity Journal 26 (5): 65-71. doi:doi:10.1016/j.tej.2013.05.004.

Chen, Yihsu, and Lizhi Wang. 2013. 'Renewable Portfolio Standards in the Presence of Green Consumers and Emissions Trading'. Networks and Spatial Economics 13 (2): 149-81. doi:10.1007/s11067-012-9176-0.

Criqui, Patrick. 1996. 'International Markets and Energy Prices: The POLES Model', Editors: J.B. Lesourd, J. Percebois and F. Valette. London, New York, Routledge, , 14-29.

DECC. 2013a. 'Electricity Generation Costs'. London, UK: Department of Energy \& Climate Change (DECC).

2013b. 'Investing in Renewable Technologies - CfD Contract Terms and Strike Prices'. London, UK: Department of Energy \& Climate Change (DECC).

2014a. 'Digest of United Kingdom Energy Statistics 2014'. A Nationals Statistics Publication. London, UK: Department of Energy \& Climate Change (DECC).

2014b. 'UK Energy in Brief 2014'. A National Statistics Publication. London, UK: Department of Energy \& Climate Change (DECC).

EC. 2013. 'EU Energy, Transport and GHG Emissions Trends to 2050. Reference Scenario 2013'. Brussels,

Belgium:

European

Commission.

IVAFSI.tu- 
berlin.delunitsIFak_VIIIwiplsharelliteraturlec_2013_eu_energy_transport_and_ghg_emissions _trends_to_2050_reference_scenario_2013.pdf.

2014. 'Questions and Answers on the Proposed Market Stability Reserve for the EU Emissions Trading System'. Brussels, Belgium: European Commission. http://europa.eu/rapid/press-release_MEMO-14-39_en.pdf.

Edwards, N. 2010. 'Interconnection with the UK and the Role of Merchant Lines.' In Printemps de La Recherche 2010 (Energie de France - EDF). Chatou, France. http://research.edf.com/fichiers/fckeditor/Commun/Innovation/conference/16juinChatou/6Nigel EdwardsEDFEnergy.pdf.

Ehrenmann, Andreas, and Yves Smeers. 2011. 'Generation Capacity Expansion in a Risky Environment: A Stochastic Equilibrium Analysis'. Operations Research 59 (6): 1332-46. doi:10.1287/opre.1110.0992.

Eide, Jan, Fernando J. de Sisternes, Howard J. Herzog, and Mort D. Webster. 2014. ' $\mathrm{CO}_{2}$ Emission Standards and Investment in Carbon Capture'. Energy Economics 45 (September): 53-65. doi:10.1016/j.eneco.2014.06.005.

Element Energy, PSCE, Imperial College, and University of Sheffield. 2014. 'Demonstrating $\mathrm{CO}_{2}$ Capture in the UK Cement, Chemicals, Iron and Steel and Oil Refining Sectors by 2025: A Techno-Economic Study'. Final Report for DECC and BIS. Cambridge, UK.

ENTSO-E. 2010. 'Ten-Year Network Development Plan 2010-2020 (TYNDP)'. Final Release. Brussels, Belgium: ENTSO-E, European Network of Transmission System Operators for Electricity. https://www.entsoe.eu/fileadmin/user_upload/_library/SDC/TYNDP/TYNDPfinal_document.pdf.

Fais, Birgit, Markus Blesl, Ulrich Fahl, and Alfred Voß. 2014. 'Comparing Different Support Schemes for Renewable Electricity in the Scope of an Energy Systems Analysis'. Applied Energy 131 (October): 479-89. doi:10.1016/j.apenergy.2014.06.046.

Finon, D. 1979. 'Scope and Limitations of Formalized Optimization of a National Energy System-the EFOM Model'. Energy Models for the European Community, an Energy Policy Special Published by IPC Science and Technology Press Limited for the Commission of the European Community, Brussels, Belgium.

Fishbone, Leslie G., and Harold Abilock. 1981. 'Markal, a Linear-Programming Model for Energy Systems Analysis: Technical Description of the Bnl Version'. International Journal of Energy Research 5 (4): 353-75. doi:10.1002/er.4440050406.

Gale, J., J. C. Abanades, S. Bachu, and C. Jenkins. 2015. 'Special Issue Commemorating the 10th Year Anniversary of the Publication of the Intergovernmental Panel on Climate Change Special Report on $\mathrm{CO}_{2}$ Capture and Storage'. International Journal of Greenhouse Gas Control, Special Issue commemorating the 10th year anniversary of the publication of the Intergovernmental Panel on Climate Change Special Report on $\mathrm{CO}_{2}$ Capture and Storage, 40 (September): 1-5. doi:10.1016/j.ijggc.2015.06.019.

GeoCapacity, E. U. 2009. 'Assessing European Capacity for Geological Storage of Carbon Dioxide'. EU GeoCapacity Project no. SES6-518318. Final Report. Denmark: EU GeoCapacity Geological Survey of Denmark and Greenland.

Gough, Clair, Laura O'Keefe, and Sarah Mander. 2014. 'Public Perceptions of $\mathrm{CO}_{2}$ Transportation in Pipelines'. Energy Policy 70 (July): 106-14. doi:10.1016/j.enpol.2014.03.039.

Greenpeace. 2011. 'Potentielle $\mathrm{CO}_{2}$-Endlager in Deutschland in Salzwasser Führenden Tiefengestein'. Auswertung der BGR-Daten durch Greenpeace. Stand 01/2011, bearbeitet von: Karsten Smid. Hamburg, Germany: Greenpeace Germany e.V.

Groenenberg, Heleen, and Heleen de Coninck. 2008. 'Effective EU and Member State Policies for Stimulating CCS'. International Journal of Greenhouse Gas Control, TCCS-4: The 4th Trondheim Conference on $\mathrm{CO}_{2}$ Capture, Transport and Storage, 2 (4): 653-64. doi:10.1016/j.jjggc.2008.04.003.

Gürkan, Gül, and Romeo Langestraat. 2014. 'Modeling and Analysis of Renewable Energy Obligations and Technology Bandings in the UK Electricity Market'. Energy Policy 70 (July): 85-95. doi:10.1016/j.enpol.2014.03.022. 
Hazeldine, Staurt. 2009. 'Carbon Capture and Storage: UK's Fourth Energy Pillar, or Broken Bridge?' Working Paper SCCS 2009-03. Edinburgh, UK: Scottish Centre for Carbon Storage.

Hirschhausen, Christian von, Johannes Herold, and Pao-Yu Oei. 2012. "How a "Low Carbon" Innovation Can Fail - Tales from a "Lost Decade" for Carbon Capture, Transport, and Sequestration (CCTS).' Economics of Energy \& Environmental Policy 2: 115-23.

Houses of Parliament. 2012. 'Low Carbon Technologies for Energy-Intensive Industries'. 403. London, UK: Parliamentary Office of Science \& Technology.

Hu, Jing, Wina Crijns-Graus, Long Lam, and Alyssa Gilbert. 2015. 'Ex-Ante Evaluation of EU ETS during 2013-2030: EU-Internal Abatement'. Energy Policy 77 (February): 152-63. doi:10.1016/j.enpol.2014.11.023.

IPCC. 2005. 'IPCC Special Report on Carbon Dioxide Capture and Storage'. Geneva, Switzerland: Intergovernmental Panel on Climate Change (IPCC).

2014. 'Climate Change 2014: Synthesis Report. Contribution of Working Groups I, II and III to the Fifth Assessment Report of the Intergovernmental Panel on Climate Change'. Geneva, Switzerland: IPCC.

Johnson, N., V. Krey, D. McCollum, S. Rao, K. Riahi, and J. Rogelj. 2015. 'Stranded on a Low-Carbon Planet: Implications of Climate Policy for the Phase-out of Coal-Based Power Plants'. Technological Forecasting and Social Change 90 (Part A): 89-102. doi:10.1016/j.techfore.2014.02.028.

Kazmierczak, Tomasz, Ruut Brandsma, Filip Neele, and Chris Hendriks. 2008. 'Algorithm to Create a CCS Low-Cost Pipeline Network'. Energy Procedia 1 (1): 1617-23.

Kemp, Alexander G., and Sola Kasim. 2013. 'The Economics of $\mathrm{CO}_{2}$-EOR Cluster Developments in the UK Central North Sea'. Energy Policy 62 (November): 1344-55. doi:10.1016/j.enpol.2013.07.047.

Kemper, Jasmin. 2015. 'Biomass and Carbon Dioxide Capture and Storage: A Review'. International Journal of Greenhouse Gas Control, Special Issue commemorating the 10th year anniversary of the publication of the Intergovernmental Panel on Climate Change Special Report on $\mathrm{CO}_{2}$ Capture and Storage, 40 (September): 401-30. doi:10.1016/j.ijggc.2015.06.012.

Kjärstad, Jan, Joris Morbee, Mikael Odenberger, Filip Johnsson, and Evangelos Tzimas. 2013. 'Modelling Large-Scale CCS Development in Europe Linking Techno-Economic Modelling to Transport Infrastructure'. Energy Procedia, GHGT-11, 37: 2941-48. doi:10.1016/j.egypro.2013.06.180.

Knoope, M. M. J., A. Ramírez, and A. P. C. Faaij. 2015. 'The Influence of Uncertainty in the Development of a $\mathrm{CO}_{2}$ Infrastructure Network'. Applied Energy 158 (November): 332-47. doi:10.1016/j.apenergy.2015.08.024.

Kobos, Peter H., Leonard A. Malczynski, David J. Borns, and Brian J. McPherson. 2007. 'The "String of Pearls": The Integrated Assessment Cost and Source-Sink Model'. Conference Proceedings of the 6th Annual Carbon Capture \& Sequestration Conference. Pittsburgh, PA, USA.

Kunz, Friedrich, and A. Zerrahn. 2015. 'Benefits of Coordinating Congestion Management in Electricity Transmission Networks: Theory and Application to Germany'. Utilities Policy Available online 21 October 2015 (October): 1-12. doi:10.1016/j.jup.2015.09.009.

La Tene Maps. 2011. 'EWEA's 20 Year Offshore Network Development Master Plan'. Map. Brussels, Belgium:

EWEA. http://www.ewea.org/fileadmin/ewea_documents/documents/publications/reports/European_O ffshore_Wind_Farm_Projects.pdf?utm_source=offshore\&utm_medium=mapDiagram\&utm_ca mpaign= OffshoreMap.

Leader of the G7. 2015. 'Leaders' Declaration G7 Summit, 7- 8 June 2015'. Schloss Elmau, Germany.

Mendelevitch, Roman. 2014. 'The Role of $\mathrm{CO}_{2}$-EOR for the Development of a CCTS Infrastructure in the North Sea Region: A Techno-Economic Model and Applications'. International Journal of Greenhouse Gas Control 20 (January): 132-59. doi:10.1016/j.ijggc.2013.11.007. 
Middleton, Richard S., and Jeffrey M. Bielicki. 2009. 'A Scalable Infrastructure Model for Carbon Capture and Storage: SimCCS'. Energy Policy 37 (3): 1052-60. doi:DOI: 10.1016/j.enpol.2008.09.049.

Middleton, Richard S., and Jordan K. Eccles. 2013. 'The Complex Future of $\mathrm{CO}_{2}$ Capture and Storage: Variable Electricity Generation and Fossil Fuel Power'. Applied Energy 108 (August): 66-73. doi:10.1016/j.apenergy.2013.02.065.

Milligan, Ben. 2014. 'Planning for Offshore $\mathrm{CO}_{2}$ Storage: Law and Policy in the United Kingdom'. Marine Policy 48 (September): 162-71. doi:10.1016/j.marpol.2014.03.029.

Morbee, J., J. Serpa, and E. Tzimas. 2012. 'Optimised Deployment of a European $\mathrm{CO}_{2}$ Transport Network'. International Journal of Greenhouse Gas Control 7 (March): 48-61. doi:10.1016/j.ijggc.2011.11.011.

Oei, Pao-Yu, Johannes Herold, and Roman Mendelevitch. 2014. 'Modeling a Carbon Capture, Transport, and Storage Infrastructure for Europe'. Environmental Modeling \& Assessment 19 (May): 515-31. doi:10.1007/s10666-014-9409-3.

Osborne, George. 2014. 'Chancellor George Osborne's Budget 2014 Speech'. 19th March 2014. London, UK.

|lafsituberlin.delunits|Fak_VIIIwiplsharelliteratur|Chancellor_Osborne's_Budget_speech_2014freezes_CO $\mathrm{CO}_{2}$ floorprice.pdf.

Pfenninger, Stefan, Adam Hawkes, and James Keirstead. 2014. 'Energy Systems Modeling for Twenty-First Century Energy Challenges'. Renewable and Sustainable Energy Reviews 33 (May): 74-86. doi:10.1016/j.rser.2014.02.003.

Pollitt, Michael G., and Aoife Brophy Haney. 2013. 'Dismantling a Competitive Electricity Sector: The U.K.'s Electricity Market Reform'. The Electricity Journal 26 (10): 8-15. doi:10.1016/j.tej.2013.11.001.

Radoslaw, Tarkowski, Uliasz-Misiak Barbara, and Wójcicki Adam. 2009. ' $\mathrm{CO}_{2}$ Storage Capacity of Deep Aquifers and Hydrocarbon Fields in Poland - EU GeoCapacity Project Results'. Energy Procedia 1 (1): 2671-77.

Schröder, Andreas, Friedrich Kunz, Jan Meiß, R. Mendelevitch, and Christian von Hirschhausen. 2013. 'Current and Prospective Costs of Electricity Generation until 2050'. DIW Data Documentation $68 . \quad$ Berlin, Germany. http://www.diw.de/documents/publikationen/73/diw_01.c.424566.de/diw_datadoc_2013068.pdf.

Stechow, Christoph von, Jim Watson, and Barbara Praetorius. 2011. 'Policy Incentives for Carbon Capture and Storage Technologies in Europe: A Qualitative Multi-Criteria Analysis'. Global Environmental Change, Special Issue on The Politics and Policy of Carbon Capture and Storage, 21 (2): 346-57. doi:10.1016/j.gloenvcha.2011.01.011.

The Parliament of Great Britain. 2013. Energy Bill. HL Bill 30. The Stationary Office, London, UK.

World Summit of the Regions. 2014. 'The Paris Declaration - Opportunity for Bottom-Up Action in Favour of the Low Carbon Economy'. Paris, France: Regions of Climate Action. 
7 Appendix: Karush-Kuhn-Tucker conditions of the ELCO model

\subsection{The electricity sector}

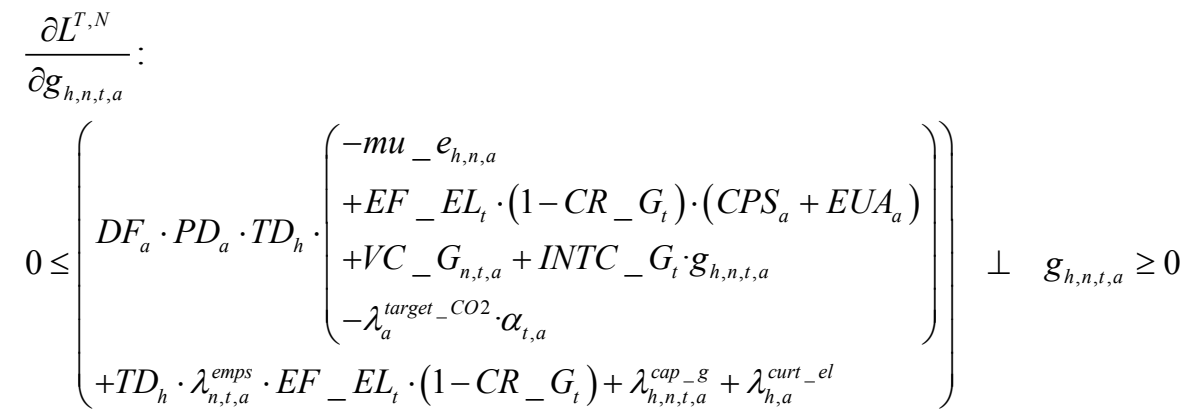

$\frac{\partial L^{T, N}}{\partial g_{-} \operatorname{cfd}_{h, n, t, a a, a}}:$

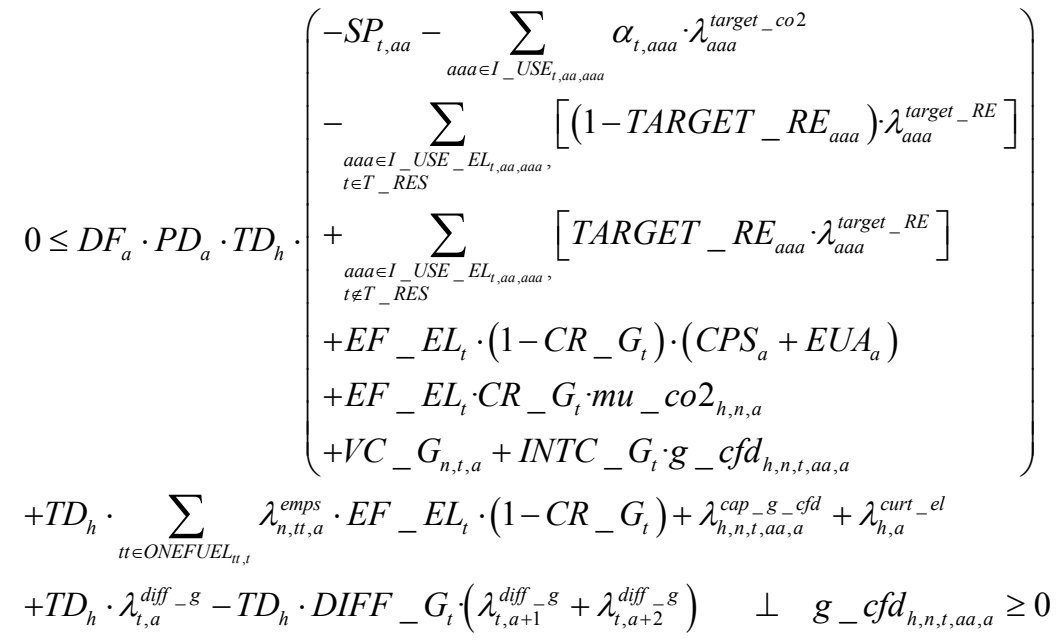

$\frac{\partial L^{T, N}}{\partial i n v_{-} g_{n, t, a}}$ :

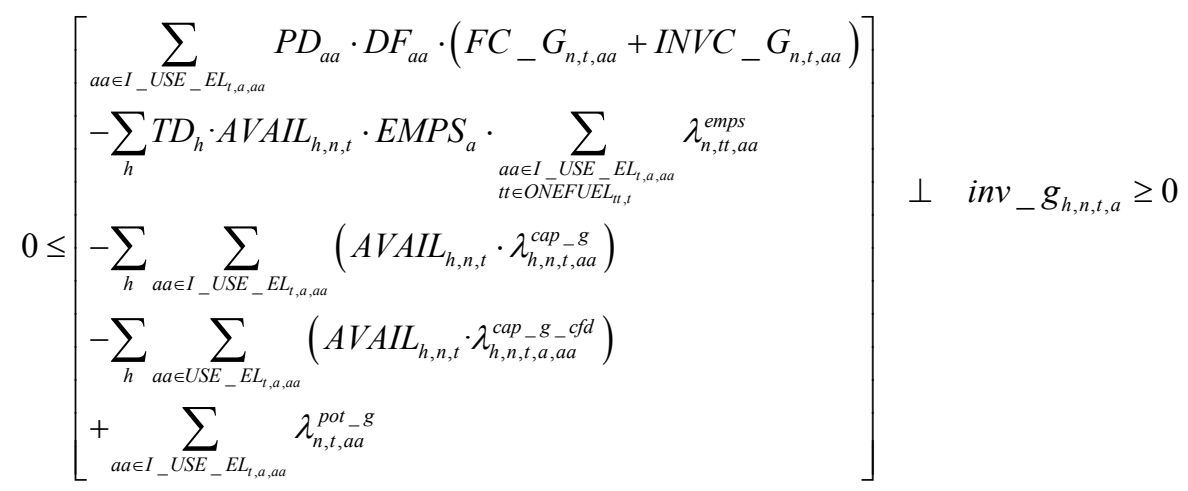




$$
\frac{\partial L^{T, N}}{\partial \lambda_{n, t, a}^{2 m p s}}
$$

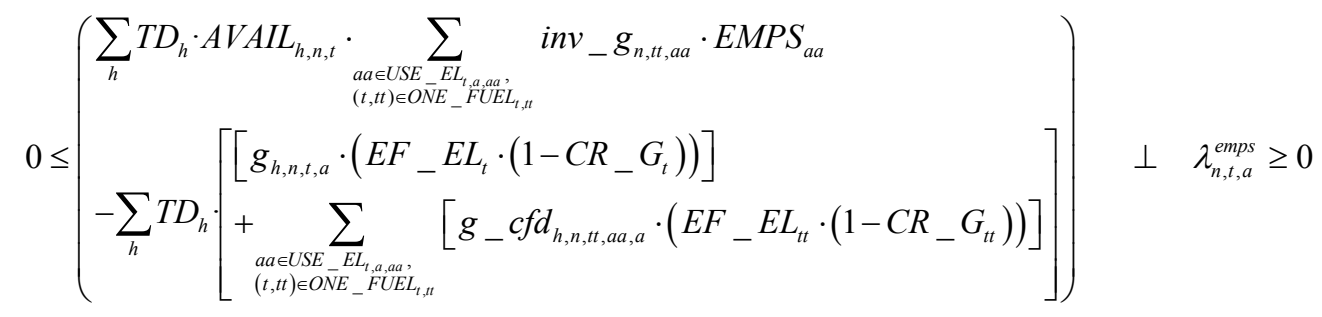

$\frac{\partial L^{T, N}}{\partial \lambda_{h, n, t, a}^{c a p}, g}:$

$0 \leq$ AVAIL $_{h, n, t} \cdot\left(I N I C A P_{-} G_{n, t, a}+\sum_{a a \in U S E_{-} E L_{l, a, a a}} i n v_{-} g_{n, t, a a}\right)-g_{h, n, t, a} \quad \perp \quad \lambda_{h, n, t, a}^{c a p} \geq 0$

$\frac{\partial L^{T, N}}{\partial \lambda_{h, n, t, a, a, a}^{c a p} g_{-a} c d}$

$0 \leq$ AVAIL $_{h, n, t} \cdot i n v_{-} g_{n, t, a a}-g_{-} c f d_{h, n, t, a a, a} \perp \quad \lambda_{h, n, t, a+a, a}^{c a p_{-} g d d} \geq 0$

$\frac{\partial L^{T, N}}{\partial \lambda_{n, t, a}^{p o t} \mathrm{~g}}:$

$0 \leq M A X_{-} I N V_{n, t}-\sum_{a a \in U S E_{-} E L_{,, a, a a}} i n v_{-} g_{n, t, a a} \quad \perp \quad \lambda_{n, t, a}^{p o t g} \geq 0$

$$
\begin{aligned}
& \frac{\partial L^{T, N}}{\partial \lambda_{t, a}^{d i f f}-g}: \\
& 0 \leq\left(S T A R T_{-} G_{t} \cdot \frac{\sum_{h, n} A V A I L_{h, n, t} \cdot T D_{h}}{\# \text { of nodes }}+\left[\sum_{h, n, a a} T D_{h} \cdot\left(g_{-} c f d_{h, n, t, a a, a-1}+g_{-} c f d_{h, n, t, a a, a-2}\right)\right]\right) \cdot D I F F_{-} G_{t} \\
& -\sum_{h, n, a a} T D_{h} \cdot g_{-} c f d_{h, n, t, a a, a} \quad \perp \quad \lambda_{t, a}^{d i f f} \_0
\end{aligned}
$$

\subsubsection{Shared environmental constraints for the electricity sector}

$$
0 \leq P D_{a} \cdot \sum_{h, n, t} T D_{h} \cdot\left[\left(g_{h, n, t, a}+\sum_{a \in \in U S E_{-} E L_{, a, a a}} g_{-} c f d_{h, n, t, a a, a}\right) \cdot \alpha_{t, a}\right] \quad \perp \quad \lambda_{a}^{\text {target_co2 }} \geq 0
$$




$$
0 \leq P D_{a} \cdot \sum_{h, n} T D_{h} \cdot\left[\begin{array}{l}
\sum_{\substack{a a \in U S E_{-} E L_{L_{a, a a}}, t \in T_{-} R E S}} g_{-} c f d_{h, n, t, a a, a}+R E S_{-} O L D_{h, n, a} \\
-R E_{-} T A R G E T_{a} \cdot \sum_{h, n} d_{h, n, a}
\end{array}\right] \perp \quad \lambda_{a}^{\text {target_} R E} \geq 0
$$

\subsection{The electricity transportation utility}

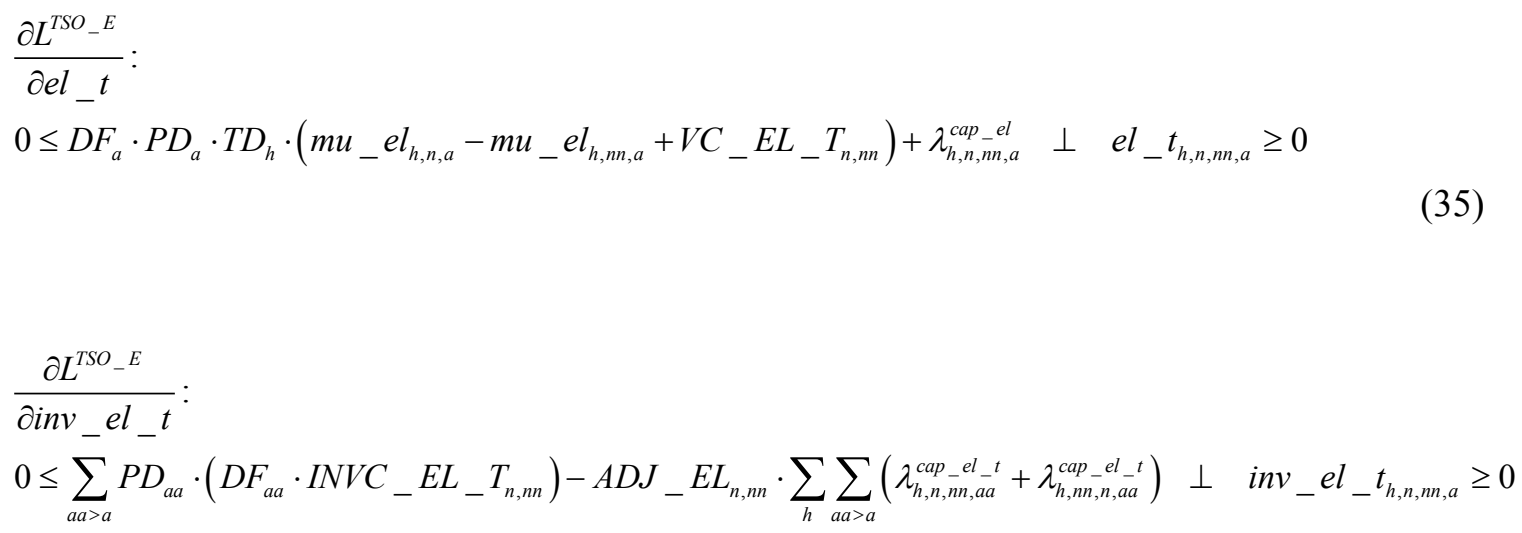

$\frac{\partial L^{T S O_{-} E}}{\partial i n v_{-} e l \_t}:$

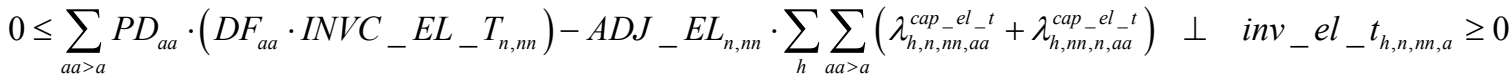

$$
\begin{aligned}
& \frac{\partial L^{T S O_{-} E}}{\partial \lambda_{h, n, n n, a}^{c a p}{ }_{-} t}: \\
& 0 \leq I N I C A P_{-} E L_{-} T_{n, n n}+\sum_{a a<a}\left(A D J_{-} E L_{n, n n} \cdot i n v_{-} e l_{-} t_{n, n n, a a}+A D J_{-} E L_{n n, n} \cdot i n v_{-} e l_{-} t_{n n, n, a a}\right)-e l_{-} t_{h, n, n n, a} \\
& \perp \quad \lambda_{h, n, n n, a}^{c a p \_e l}{ }_{-} t \geq 0
\end{aligned}
$$




\subsection{The industry sector}

$\frac{\partial L^{I, N}}{\partial c o 2_{-} c_{h, n, i, a}}:$

$0 \leq D F_{a} \cdot P D_{a} \cdot T D_{h} \cdot\left(-E U A_{a}+m u_{-} c o 2_{h, n, a}+V C_{-} C O 2_{n, i, a}\right)+\lambda_{h, n, i, a}^{m a x}+\lambda_{h, n, i, a}^{c a p} c 2_{-} c$

$\perp \quad 02 \_c_{h, n, i, a} \geq 0$

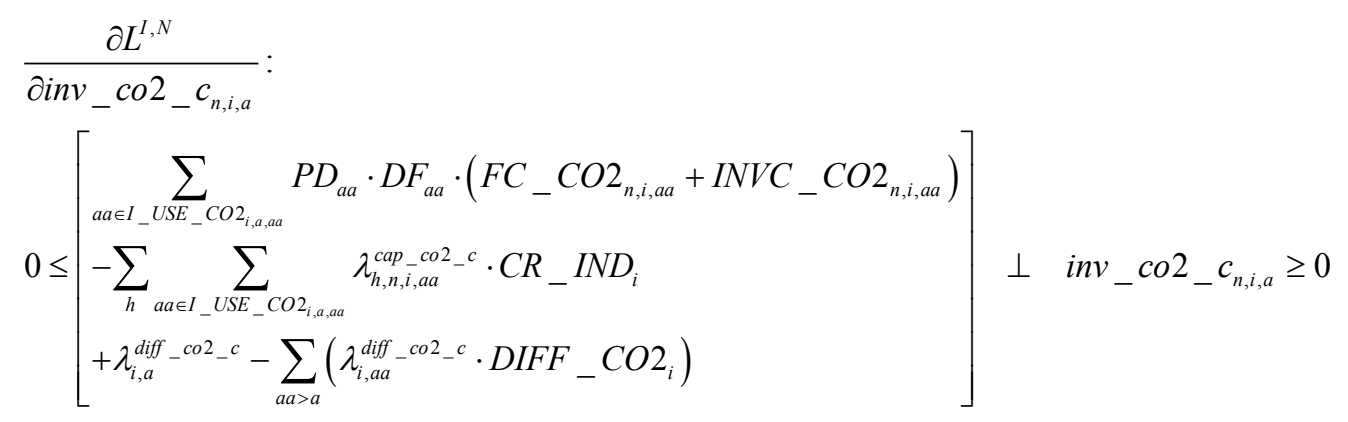

(39)

$\frac{\partial L^{I, N}}{\partial \lambda_{h, n, i, a}^{\max } \text { ind }}:$

$0 \leq C O 2 \_I N D_{h, n, i, a} \cdot C R_{-} I N D_{i}-c o 2_{-} c_{h, n, i, a} \perp \lambda_{h, n, i, a}^{\text {max }}$ ind $\geq 0$

$\frac{\partial L^{I, N}}{\partial \lambda_{h, n, i, a}^{c a p} p_{-} c c^{c}}:$

$\sum_{a a \in U S E_{-} C O 2_{i, a, a a}} i n v_{-} C O 2_{-} c_{n, i, a a} \cdot C R_{-} I N D_{i}-c 02_{-} c_{h, n, i, a} \perp \quad \lambda_{h, n, i, a}^{c a p_{-} c} \geq 0$

$\frac{\partial L^{I, N}}{\partial \lambda_{i, a}^{d i f f_{-} c 2_{-} c}}:$

$0 \leq\left(S T A R T_{-} C O 2_{i}+\sum_{n} \sum_{a a<a} i n v_{-} c 02_{-} c_{n, i, a a}\right) \cdot D I F F_{-} C O 2_{i}-\sum_{n} i n v_{-} c o 2_{-} c_{n, i, a} \quad \perp \quad \lambda_{i, a}^{\text {diff } c 02_{-} c} \geq 0$

(42) 


\subsection{The $\mathrm{CO}_{2}$ transportation utility}

$\frac{\partial L^{T S O}{ }_{-} \mathrm{CO} 2}{\partial c 0{ }_{2} t_{h, n, n, a}}:$

$0 \leq D F_{a} \cdot P D_{a} \cdot T D_{h} \cdot\left(m u_{-} c 02_{h, n n, a}-m u_{-} c 02_{h, n, a}+V C_{-} C O 2_{-} t_{n, n n}\right)+\lambda_{h, n, n n, a}^{c a p}{ }^{t} \perp c o 2_{-} t_{h, n, n n, a} \geq 0$

\section{$\frac{\partial L^{T S O_{-} E}}{\partial i n v_{-} c o 2_{-} t}$ :}

$0 \leq \sum_{a a>a} P D_{a a} \cdot\left(D F_{a a} \cdot I N V C_{-} C O 2_{-} T_{n, n n}\right)-A D J_{-} C O 2_{n, n n} \cdot \sum_{h} \sum_{a a>a}\left(\lambda_{h, n, n, a a}^{c a p+c o 2_{-} t}+\lambda_{h, n n, n, a a}^{c a p-c o 2_{-} t}\right)$

$\perp \quad$ inv_co ${ }_{-} t_{h, n, n n, a} \geq 0$

$\frac{\partial L^{T S O_{-} E}}{\partial \lambda_{h, n, n n, a}^{c a p_{-} c o 2_{-}}}:$

$0 \leq I N I C A P_{-} C O 2_{-} T_{n, n n}+\sum_{a a<a}\left(A D J_{-} C O 2_{n, n n} \cdot i n v_{-} c 02_{-} t_{n, n n, a a}+A D J_{-} C O 2_{n n, n} \cdot i n v_{-} c o 2_{-} t_{n n, n, a a}\right)$

$-c o 2 \_t_{h, n, n n, a} \perp \quad \lambda_{h, n, n n, a}^{c a p_{-} c o 2 \_t} \geq 0$

\subsection{The storage sector}

$$
\begin{aligned}
& \frac{\partial L^{S, N}}{\partial c o{ }^{-} s_{h, n, s, a}}:
\end{aligned}
$$

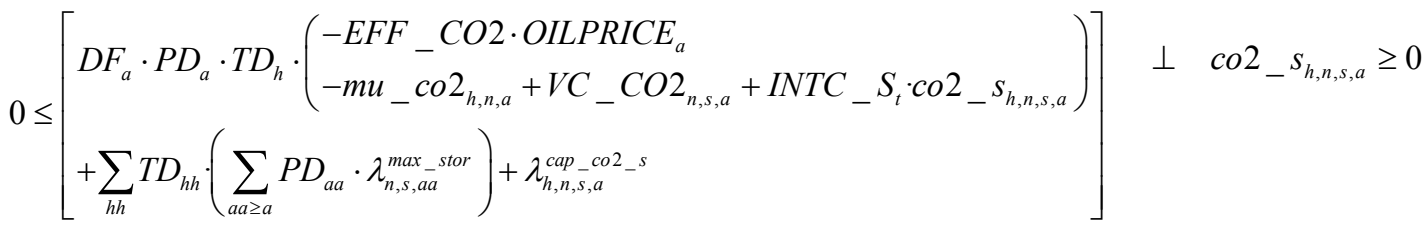

$\frac{\partial L^{S, N}}{\partial i n v_{-} c o{ }_{-} s_{n, s, a}}:$

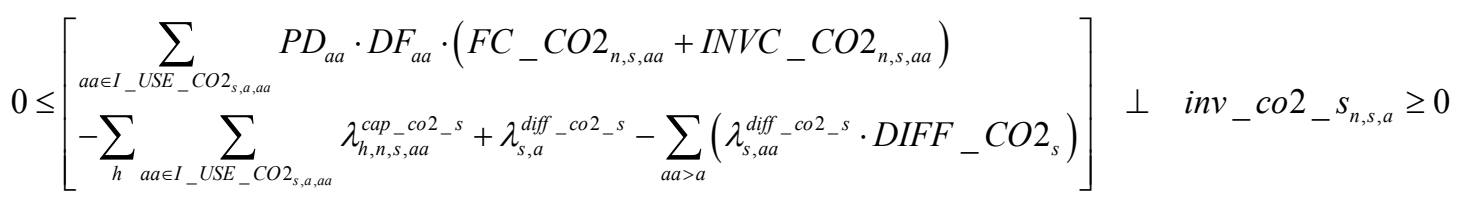

$$
\begin{aligned}
& \frac{\partial L^{S, N}}{\partial \lambda_{h, n, s, a}^{c a p} p_{-} s}: \\
& 0 \leq \sum_{a a \in U S E_{-} C O 2_{s, a, a a}} i n v_{-} C O 2_{-} s_{n, s, a a}-c 02_{-} s_{h, n, s, a} \quad \perp \quad \lambda_{h, n, s, a}^{c a p}-c 02_{-} s \geq 0
\end{aligned}
$$


$\frac{\partial L^{\mathrm{S}, N}}{\partial \lambda_{n, s, a}^{\max } \text { stor }}:$

$0 \leq M A X_{-} S T O R_{n, s}-\sum_{h}\left(T D_{h} \cdot \sum_{a a \leq a} P D_{a a} \cdot c 02_{-} s_{h, n, s, a a}\right) \perp \lambda_{n, s, a}^{\max s t o r} \geq 0$

$\frac{\partial L^{S, N}}{\partial \lambda_{s, a}^{d i f f_{-} c o L_{-} s}}:$

$0 \leq\left(S T A R T_{-} C O 2_{s}+\sum_{n} \sum_{a a<a} i n v_{-} C O 2_{-} s_{n, s, a a}\right) \cdot D I F F_{-} C O 2_{s}-\sum_{n} i n v_{-} c 02_{-} s_{n, s, a} \quad \perp \quad \lambda_{s, a}^{\text {diff } c o 2_{-} s} \geq 0$

\subsection{Market clearing conditions across all sectors}

$$
\begin{aligned}
0= & \sum_{t}\left(g_{h, n, t, a}+\sum_{a a \in U S E_{-} E L_{l, a, a a}} g_{-} c f d_{h, n, t, a a, a}\right)+\sum_{n n} e l_{-} t_{h, n n, n, a}-\sum_{n n} e l_{-} t_{h, n, n n, a}-\left(D_{h, n, a}-R E S_{-} O L D_{h, n, a}\right) \\
& m u_{-} e_{h, n, a}(\text { free }) \quad \forall h, n, a
\end{aligned}
$$

$$
\begin{aligned}
& \frac{\partial L^{T, N}}{\partial \lambda_{h, a}^{\text {curt } \_l}}: \\
& 0 \leq \sum_{n}\left(D_{h, n, a}-R E S \_O L D_{h, n, a}\right)-\sum_{n, t}\left(g_{h, n, t, a}+\sum_{a a \in U S E_{-} E L_{h, a, a a}} g_{-} c f d_{h, n, t, a a, a}\right) \perp \lambda_{h, a}^{\text {curt el }} \geq 0
\end{aligned}
$$

$$
0=-\left(\begin{array}{r}
\sum_{t}\left(\sum_{a a \in U S E_{-} E L_{t, a, a a}} g_{-} c f d_{h, n, t, a a, a} \cdot E F_{-} E L_{t} \cdot C R_{-} G_{t}\right) \\
+\sum_{i} c o 2_{-} c_{h, n, i, a} \\
+\sum_{n n} c o 2_{-} t_{h, n n, n, a}-\sum_{n n} c o 2_{-} t_{h, n, n n, a}-\sum_{s} c o 2_{-} s_{h, n, s, a}
\end{array}\right) \quad m u_{-} c o 2_{h, n, a}(\text { free }) \quad \forall h, n, a
$$

